\title{
Bergen Earth system model (BCM-C): model description and regional climate-carbon cycle feedbacks assessment
}

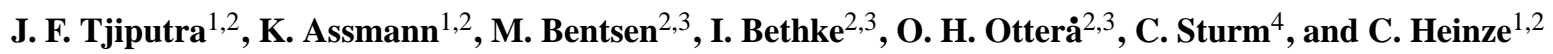 \\ ${ }^{1}$ University of Bergen, Department of Geophysics, Allégaten 70, 5007 Bergen, Norway \\ ${ }^{2}$ Bjerknes Centre for Climate Research, Allégaten 55, 5007, Bergen, Norway \\ ${ }^{3}$ Nansen Environmental and Remote Sensing Center, Thormølensgate 47, 5006 Bergen, Norway \\ ${ }^{4}$ Bert Bolin Centre for Climate Research, Svante Arrhenius väg 8 C, 10691 Stockholm, Sweden
}

Received: 12 May 2009 - Published in Geosci. Model Dev. Discuss.: 8 July 2009

Revised: 8 December 2009 - Accepted: 15 December 2009 - Published: 12 February 2010

\begin{abstract}
We developed a complex Earth system model by coupling terrestrial and oceanic carbon cycle components into the Bergen Climate Model. For this study, we have generated two model simulations (one with climate change inclusions and the other without) to study the large scale climate and carbon cycle variability as well as its feedback for the period 1850-2100. The simulations are performed based on historical and future IPCC $\mathrm{CO}_{2}$ emission scenarios. Globally, a pronounced positive climate-carbon cycle feedback is simulated by the terrestrial carbon cycle model, but smaller signals are shown by the oceanic counterpart. Over land, the regional climate-carbon cycle feedback is highlighted by increased soil respiration, which exceeds the enhanced production due to the atmospheric $\mathrm{CO}_{2}$ fertilization effect, in the equatorial and northern hemisphere mid-latitude regions. For the ocean, our analysis indicates that there are substantial temporal and spatial variations in climate impact on the air-sea $\mathrm{CO}_{2}$ fluxes. This implies feedback mechanisms act inhomogeneously in different ocean regions. In the North Atlantic subpolar gyre, the simulated future cooling of SST improves the $\mathrm{CO}_{2}$ gas solubility in seawater and, hence, reduces the strength of positive climate carbon cycle feedback in this region. In most ocean regions, the changes in the Revelle factor is dominated by changes in surface $p \mathrm{CO}_{2}$, and not by the warming of SST. Therefore, the solubility-associated positive feedback is more prominent than the buffer capacity feedback. In our climate change simulation, the retreat of Southern Ocean sea ice due to melting allows an additional $\sim 20 \mathrm{Pg} \mathrm{C}$ uptake as compared to the simulation without climate change.
\end{abstract}

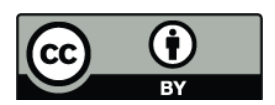

Correspondence to: J. F. Tjiputra (jerry.tjiputra@bjerknes.uib.no)

\section{Introduction}

Understanding the interactions between climate and the global carbon cycle is crucial to accurately project future climate change. Unfortunately, empirical evidence for global climate-carbon cycle interactions, as well as their feedbacks for time scales relevant to the current climate change (i.e., decadal to centennial time scales), is very limited. Therefore, such an assessment has to be attempted by applying comprehensive, fully interactive global climate-carbon cycle models (Heimann and Reichstein, 2008). Recently, state-ofthe-art coupled climate-carbon cycle models have been used as key elements in understanding present and future climate change. They include sophisticated interactions between the atmosphere, ocean circulation and marine biogeochemical cycles, terrestrial biosphere as well as sea-ice. Previous intercomparisons (Friedlingstein et al., 2006) have proven that these models, despite their notable uncertainties, are essential for predicting future interactions and feedbacks between climate-carbon components in the complex Earth system.

The Bergen Climate Model "BCM" (Furevik et al., 2003) is a coupled atmosphere ocean general circulation model (AOGCM) that has been well-tested for both mean and transient climate conditions. It is generally able to capture the main features of the observed short- and long-term climate variability, such as the radiative forcing, freshwater fluxes, ENSO, NAO modes within realistic temporal and spatial variability. In addition, the BCM has been applied to integrate past climate scenarios for the United Nations Intergovernmental Panel on Climate Change (UN-IPCCv4) report (Randall et al., 2007). Nevertheless, the BCM has, so far, been a purely physical AOGCM lacking oceanic and terrestrial carbon cycle components necessary for the inclusion of carbon cycle feedbacks in future climate projections.

Published by Copernicus Publications on behalf of the European Geosciences Union. 
In this study, we couple terrestrial and oceanic carbon cycle models to the BCM, creating the BCM-C. The model is applied to simulate climate-carbon cycle projections for the period 1850-2100. The simulations are compared with observations and validated towards other Earth system model projections. Furthermore, we analyse the regional variability of mechanisms responsible for controlling the local and global climate-carbon cycle feedback.

The manuscript is organised as follows, Sect. 2 describes the different model components used in this study as well as our coupling strategy, Sect. 3 describes the configuration and settings adopted in the model simulations performed, Sect. 4 summarizes the results and analysis of the model simulations and, finally, the manuscript is closed with discussions and conclusions.

\section{Model description}

The BCM-C consists of global atmospheric and oceanic general circulation models coupled to oceanic and terrestrial carbon cycle models. The newly coupled model is able to interactively simulate the known global carbon-cycles processes, including the radiative feedback necessary for climate change simulations. Each component of the BCM-C is described in more detail in the following subsections.

\subsection{Atmospheric circulation model}

The atmosphere component is the spectral atmospheric general circulation model ARPEGE from Météo-France (Déqué et al., 1994). The ARPEGE model, as applied in this study, is described in detail in Furevik et al. (2003) and its major features are briefly summarized here.

In ARPEGE, the representation of most model variables is spectral (i.e., scalar fields are decomposed on a truncated basis of spherical harmonic functions). In the present study, ARPEGE is run with a truncation at wave number $63\left(T_{\mathrm{L}} 63\right)$, and a time step of $1800 \mathrm{~s}$. the grid point calculations are done with a grid of horizontal resolution of about $2.8^{\circ} \times 2.8^{\circ}$. A total of 31 levels is employed, ranging from the surface to $0.01 \mathrm{hPa}$ (20 layers in the troposphere).

The physical parameterization is divided into several explicit schemes, which each calculate the flux of mass, energy and/or momentum due to a specific physical process. Different from the model description in Déqué et al. (1994), the version used in BCM contains a convective gravity drag parameterization (Bossuet et al., 1998), a new snow scheme (Douville et al., 1995), a refined orographic gravity wave drag scheme (Lott and Miller, 1997; Lott, 1999; Catry et al., 2008) and modifications in deep convection and soil vegetation schemes.

The vertical diffusion scheme is a first order eddyviscosity scheme (Loui, 1979; Loui et al., 1982; Geleyn, 1988), which is popular in global models because of its sim- plicity and physical clarity. In the original version of the scheme, a feedback could be activated in the case of a very cold surface. A cooling surface involved an increase in the stability which, in turn, would prevent any heating by the atmosphere. This would accelerate the cooling until reaching a radiative balance that could be very cold in the polar night. This phenomenon led to a significant cold bias in the global temperature in earlier versions of BCM. To avoid the phenomenon, a limitation has been added to the Richardson number: if $R i>0$, then $R i \leftarrow \frac{R i}{\left(1+R i / R i_{c r}\right)}$ and $U_{\text {ric }}=1 / R i_{\mathrm{cr}}$, where $R i_{\mathrm{cr}}$ is an upper limit for positive Richardson numbers. The standard value for $U_{\text {ric }}$ is 0 , which comes to not applying the above limitation. In the present version of BCM, a value of 1.2 is used for $U_{\text {ric }}$.

In ARPEGE, there is a mass drift due to the nonconservative form of the discretized continuity equation (M. Deque, personal communication, 2009). In order to correct this, the following method has been used: every $6 \mathrm{~h}$ the partial pressure of dry air averaged over the globe is calculated. This value is then compared with the value $983.2 \mathrm{hPa}$, which is the ERA40 average value. The difference (loss or gain of mass) is then added to the surface pressure uniformly (less than $0.1 \mathrm{hPa}$ per month). With this correction, total air mass can have a seasonal cycle or a long-term drift (due to variations in water vapour content), but no drift due to nonconservation. The drawback, however, is the uniform correction, since the sources and sinks may be local.

\subsection{Oceanic circulation model}

The ocean component is the Miami Isopycnic Coordinate Ocean Model (MICOM) based on (Bleck et al., 1992) with the following updates. The original MICOM uses potential density with the reference pressure at $0 \mathrm{db}$ as vertical coordinate $\left(\sigma_{o}\right.$-coordinate). This ensures that the very different flow and mixing characteristic in neutral and dia-neutral directions is well represented near the surface since isopycnals and neutral surfaced are similar near the reference pressure. For pressure levels that differ substantially from the reference pressure, this does not hold. Here, a reference pressure of $2000 \mathrm{db}$ is used. The selection of $2000 \mathrm{db}$ as the reference pressure is motivated by the study of McDougall and Jackett (2005), who argue that these isopycnals are a reasonable compromise in approximating neutral surfaces of the world Ocean. In contrast, isopycnals referenced to $0 \mathrm{db}$ generally becomes significantly non-neutral in the deep ocean. The pressure gradient force (PGF) is estimated using in situ density based on the formulation of Janic (1977), which reduces problems with the dynamics away from the reference pressure compared to the traditional approach in isopycnic models where potential density replaces in situ density in the PGF calculation. The main drawback of using $2000 \mathrm{db}$ reference pressure is a poor representation of stratification in some areas, mainly in high latitude haloclines, especially in parts of the Southern Ocean. 
For tracer advection and layer thickness, the current MICOM uses incremental remapping (Dukowicz and Baumgardner, 2000) adapted to the grid staggering of MICOM. The algorithm is computationally rather expensive compared to other second order methods, but the cost of adding additional tracers is modest. In contrast to the original transport method, incremental remapping ensures monotonicity of the tracers.

The treatment of diapycnic mixing follows the standard MICOM approach of a background diffusivity dependent on the local stability and is implemented using the scheme of McDougall and Dewar (1998). To incorporate shear instability and gravity current mixing, a Richardson number dependent diffusivity has been added to the background diffusivity. This has greatly improved the water mass characteristics downstream of overflow regions. Lateral turbulent mixing of momentum and tracers is parameterized by Laplacian diffusion, and layer interfaces are smoothed with biharmonic diffusion.

The mixed layer depth (MLD) computed in MICOM is parameterized after Gaspar (1988), through a turbulent kinetic energy balance of a one-dimensional mixed layer. It belongs to the family of Kraus and Turner (1967) type mixed-layer models. The simulated MLD is consistent with separate postprocessing determination of MLD based on the prognostic density or temperature criteria.

With the exception of the equatorial region, the ocean grid in our configuration is almost regular with horizontal grid spacing approximately $2.4^{\circ} \times 2.4^{\circ}$. In order to better resolve the dynamics near the equator, the horizontal spacing in the meridional direction is gradually decreased to $0.8^{\circ}$ along the Equator. The model has a time step of $4800 \mathrm{~s}$ and a stack of 34 isopycnic layers in the vertical coordinate, with potential densities ranging from 1029.514 to $1037.800 \mathrm{~kg} \mathrm{~m}^{-3}$. A non-isopycnic surface mixed layer on top provides the linkage between the atmospheric forcing and the ocean interior.

\subsection{Sea-ice dynamical model}

In this study, we applied the original sea-ice model, which had been integrated into MICOM. It is a dynamicthermodynamic sea-ice model. It shares the same horizontal grid resolution. The heat, salt, and water flux exchanges between the ocean and sea-ice are handled internally. The thermodynamic part of the sea-ice model is based on Drange and Simonsen (1996). The model consists of one ice and one snow layer assuming a linear temperature profile in each layer. The temperature profile is determined by the freezing temperature at the water/ice boundary, and the balance between turbulent, radiative and conductive heat fluxes at the snow/air boundary. The dynamical part of the sea-ice model uses viscous-plastic rheology based in the implementation of Harder (1996).
As an alternative to the original sea-ice model, the sea-ice model GELATO (Salas-Melia, 2002) can also be used as the sea ice component in BCM-C. As opposed to the original sea-ice, GELATO is a multi-category sea-ice model (thickness dependent), allowing a more precise treatment of thermodynamics. The large scale climate state and variability modes simulated by BCM using the GELATO sea-ice model are discussed in Otterå et al. (2009).

\subsection{Ocean carbon cycle model}

The BCM-C adopts the Hamburg Ocean carbon cycle (HAMOCC5.1) model, which is based on the original work by Maier-Reimer (1993) with the extensions of MaierReimer et al. (2005). The current version of the model includes an NPZD-type (nutrient, phytoplankton, zooplankton and detritus) ecosystem model following Six and MaierReimer (1996) with multi-nutrient co-limitations (Aumont et al., 2003). The model contains over 30 biogeochemical tracers, which include dissolved inorganic carbon, total alkalinity, oxygen, nitrate, phosphate, silicate, iron, phytoplankton and zooplankton. Fixed Redfield ratios (i.e., P:N:C: $\Delta \mathrm{O}_{2}$ ) are used for production and remineralization of biogenic matter. In addition to temperature and light (i.e., according to Michaelis-Menten kinetics), the phytoplankton growth rate is also co-limited by nitrate, phosphate and iron concentrations. The modelled bulk phytoplankton concentration is then divided into diatom and coccolithophore compartments, based on silicate concentration. Such a silicate dependent formulation yields higher diatom fraction when the prognostic silicate concentration is high. The remaining phytoplankton is then assumed to be coccolithophore. In the tropical oligotrophic nitrate-depleted regions, the marine ecosystem module accounts for atmospheric nitrogen fixation as for cyanobacteria growth. The nitrogen fixation is parameterized as the relaxation of surface layer deviation of the N:P ratio of nutrients. Thus, whenever there is more phosphate than nitrate (i.e., based on the Redfield ratio) in the surface layer, algae fix atmospheric nitrogen which in the model is immediately recycled to nitrate. Particulate organic carbon, produced due to the ecosystem dynamics, is exported out of the euphotic zone with a constant sinking speed. Once exported, the organic matter is remineralized at depth, and the nonremineralized particles are collected by the sediment.

The inorganic carbon chemistry in the HAMOCC5.1 model is based on Maier-Reimer and Hasselmann (1987) and is updated with the OCMIP (Ocean Carbon-cycle Model Intercomparison Project) carbon chemistry protocols. The surface $p \mathrm{CO}_{2}$ in the model is computed prognostically as a function of alkalinity, total DIC, temperature, pressure and salinity. The dissolution of calcium carbonate at depth is computed as a function of carbonate ion saturation state and a constant dissolution rate. The air-sea gas (i.e., $\mathrm{CO}_{2}$ and $\mathrm{O}_{2}$ ) exchange processes are formulated as a function of gas solubility, transfer velocity 
and the difference between partial pressure tracers in air and water following Wanninkhof (1992). The gas tracer solubilities are computed according to Weiss (1970) and Weiss (1974), whereas the gas transfer velocity depends on the Schmidt number and prognostic wind speed on the surface. Also note that the model has a 12-layer sediment model, which is applicable for future, long-term model studies, for example where the buffering of anthropogenic $\mathrm{CO}_{2}$ through calcium carbonate dissolution from the sea floor becomes important.

\subsection{Terrestrial carbon model}

The Lund-Postdam-Jena Model (LPJ) (Sitch et al., 2003) is a large-scale terrestrial carbon cycle model, which includes dynamical vegetation. It implements terrestrial photosynthesis, respiration, resource competition, tissue turnover, dynamic vegetation population with 10 plant functional types (PFTs), soil organic and litter dynamic as well as natural fire occurrence. The soil hydrology, with 2-level soil moisture, is treated by LPJ (i.e., no direct coupling to ARPEGE). For each model grid, carbon storage is allocated into four compartments, vegetation, litter, fast and slowly overturning soil carbon pool. The current version of the model does not include land use change. The LPJ has a horizontal resolution of approximately $2.5^{\circ} \times 2.5^{\circ}$ with monthly model time step. The $2.5^{\circ}$ resolution corresponds to the atmospheric model, as they run on the same grid (over land).

\subsection{Coupling strategy}

The OASIS coupler (Terray et al., 1995), which has been developed at the National Centre for Climate Modelling and Global Change (CERFACS), Toulouse, France, has been used to couple ARPEGE with MICOM. OASIS synchronizes different model components, such that the fastest running model can wait for the other until all components are integrated at a complete prescribed time interval (i.e., one day). It also efficiently reads, interpolates, and transfers the exchange fields between ARPEGE and MICOM.

The HAMOCC5.1 is coupled directly into MICOM and, therefore, has identical temporal, horizontal and vertical resolutions. This coupling allows all biogeochemical tracers within HAMOCC5.1 to be advected along MICOM's isopycnic coordinates, which resemble the real structure of the water column and avoid artificial mixing and advection in the ocean interior. The caveat of such coupling includes the problem with massless layers in the outcrop regions and the introduction of bulk mixed layer on the model topmost layer. The marine biological production occurs within the euphotic zone, which is formulated to be the minimum between $90-\mathrm{m}$ depth and the mixed layer depth simulated by MICOM. The biogeochemical tracers are advected by the prognostic physical fields simulated by MICOM. In addition, variables such as temperature, salinity, pressure and density used in the computation of ocean $p \mathrm{CO}_{2}, \mathrm{pH}$ and carbonate ion fields are also taken from MICOM. More detail on HAMOCC-MICOM coupling, together with series of sensitivity carbon cycle studies are discussed in Assmann et al. (2010). In their study, Assmann et al. use the identical MICOM and the respected sea-ice model, although different atmospheric forcing could result in different ice cover. They also adopt identical coupling of the model components as well as similar spatial and temporal resolution. The carbon chemistry in their study, however, is still based on the original HAMOCC model, whereas in this study it has been adjusted to the OCMIP carbon chemistry parameterization. Supplemental Fig. 1 (see http://www.geosci-model-dev.net/ 3/123/2010/gmd-3-123-2010-supplement.pdf) illustrates the performance of the HAMOCC5.1 in simulating the observed biogeochemical tracers' distributions when it is forced by NCEP (Assmann et al., 2010), as compared to AOGCM as shown in this study. Overall, the differences in the modeldata fit are relatively small between the two model configurations.

The LPJ is integrated annually at the end of each model year, and forced by monthly ARPEGE output fields of temperature, precipitation, cloud coverage and number of rainy days per month. The number of rainy days per month is randomly distributed into quasi-daily values, which is normalized to the Climate Research Unit (CRU) monthly precipitation values. The coupling of $\mathrm{CO}_{2}$ gas exchange occurs at the end of every model year, where an updated atmospheric $\mathrm{CO}_{2}$ concentration is computed based on the annual fluxes between the atmosphere and the ocean or land. Thus, the atmospheric $\mathrm{CO}_{2}$ concentration is only updated once a year for the land and ocean. Currently, the albedo feedback, due to changes in the terrestrial PFT, is not implemented, but it is part of our future research plans. In all of the model simulations, no form of flux adjustments is applied to the model.

\section{Model simulations}

A set of three model simulations adopting different configurations and forcing fields was carried out. The first is designed to analyse and evaluate the steady state simulated by the model, whereas the latter two are intended latter two are intended to analyse in detail the climate-carbon cycle feedback in the model.

\subsection{Experiment REF}

The REF model simulation is performed for spin up. The fully coupled BCM-C is integrated for 600 years applying constant pre-industrial atmospheric $\mathrm{CO}_{2}$ concentration at $284.7 \mathrm{ppm}$ (i.e., estimated value for year 1850). The goal of the REF simulation is to generate a pre-industrial (i.e., 1850 AD) steady state climate, which can be used for the initial state of COU and UNC simulations (see below). 


\subsection{Experiment COU}

For the second simulation, we initialized the BCM-C based on the final state achieved from the REF and integrated from 1850 to 2099 forced only by anthropogenic $\mathrm{CO}_{2}$ emissions. For the period 1850-1999, carbon emissions based on observed records of fossil fuel burning and deforestation (Marland et al., 2005) are used, whereas for the period 2000-2099, the IPCC SRES-A2 emission scenario (Houghton and Hackler, 2002) is used.

\subsection{Experiment UNC}

In the third simulation, we prescribed the atmospheric $\mathrm{CO}_{2}$ concentration from the $\mathrm{COU}$, but the radiative effect of atmospheric $\mathrm{CO}_{2}$ change is removed in the model (i.e., the atmospheric circulation model interacts with a constant $284.7 \mathrm{ppm}$ $\mathrm{CO}_{2}$ concentration). Therefore, unlike in $\mathrm{COU}$, the simulated carbon cycle in UNC experiences no climate change effect (e.g., warming, change in atmosphere and ocean circulation, etc.). Experiment UNC was designed such that its difference with experiment COU represents how future climate change affect both the terrestrial and oceanic carbon uptake. This set-up is similar to that of the C4MIP study (Friedlingstein et al., 2006).

\section{Results and evaluation}

\subsection{Pre-industrial reference run}

In general, after 600 years of spin-up (REF), the BCM-C is able to reach a steady climate state, which is to a large degree consistent with observations. The performance of spatiallyaveraged climate parameters simulated by BCM-C in REF is compared to the observed climatology state and summarized using a Taylor diagram as shown in Fig. 1. The Taylor diagram evaluates the model performance as a function of normalized standard deviation, centered root-mean-square (RMS), and pattern correlation (Taylor, 2001). All simulated variables are normalized by the respective observed variable's standard deviation, thus, a perfect model-data fit would reside in the observation point (i.e., $\sigma=1$, RMS $=0$, and $r=1$ ). The model is able to reproduce the observed 2-m surface air temperature "sat" and sea surface temperature "sst" quite realistically in terms of spatial and actual amplitude variabilities, shown by the correlation and normalized standard deviation close to unity. The simulated surface salinity "sss" deviates noticeably from the observation with normalized standard deviation of only 0.5 . This discrepancy is mainly due to the overestimated Arctic water salinity in the model compared to the LEVITUS climatology SSS. The simulated precipitation "prc" and mean sea-level pressure "slp" variability are comparable to the observations. Biases in the precipitation are mainly due to a weaker precipitation rate over the ocean than that observed, whereas discrepancies between the observed and modelled mean sea-level pressure are caused by excessive high pressure over the Arctic, which resulted in weaker Icelandic and Aleutian low pressure systems. Additionally, the atmospheric meridional pressure gradient in the Antarctic circumpolar region is too weak. This resulted in weak surface winds there. Similar evaluation using the Taylor diagram for different seasons show similar model-data fit patterns (see supplemental Fig. 2).

The marine carbon cycle in REF produces the observed main characteristics of ocean biogeochemistry, which include global distributions of nutrients, DIC, alkalinity, High Nutrient-Low Chlorophyll regions, regional net primary production and air-sea $\mathrm{CO}_{2}$ fluxes. The pre-industrial ocean tracer distribution simulated by HAMOCC5.1 is discussed in Assmann et al. (2010). We also note that because of the different atmospheric forcing fields used to force the ocean physics, the ocean biogeochemical tracer distributions are slightly different, despite nearly identical carbon cycle processes (also see supplemental Fig. 1). Within the last 100 model years of the spinup run, the ocean carbon cycle yields steady annual airsea $\mathrm{CO}_{2}$ fluxes, net primary production, particle organic carbon export and calcite export of $0 \pm 0.2,39 \pm 2.0,9.5$, and $0.6 \mathrm{Pg} \mathrm{Cyr}^{-1}$,respectively (as shown in supplemental Fig. 3, see http://www.geosci-model-dev.net/3/123/2010/ gmd-3-123-2010-supplement.pdf). The model simulates well the fundamental characteristics of oceanic $\mathrm{CO}_{2}$ fluxes patterns, with dominant outgassing in the Equatorial Pacific and uptakes in the North Atlantic, and the Southern Ocean.

The interannual land-atmosphere carbon fluxes simulated in REF have maximum variability range of $\pm 2.0 \mathrm{Pg} \mathrm{C} \mathrm{yr}^{-1}$. The pre-industrial equilibrium global terrestrial vegetation, soil and litter carbon content simulated by BCM$\mathrm{C}$ are 735,1380 , and $145 \mathrm{PgC}$, respectively, consistent with the range of other terrestrial model studies (Kucharik et al., 2000; Sitch et al., 2003) (see also supplemental Fig. 4, http://www.geosci-model-dev.net/3/123/2010/ gmd-3-123-2010-supplement.pdf).

\subsection{Model projections of global carbon cycle and climate change}

The projected modern-period anthropogenic carbon uptake simulated in the COU compares reasonably well with estimates from other studies. For example, during the 1990s, the model simulates annual means of terrestrial and oceanic carbon sink of 1.59 and $2.43 \mathrm{Pg} \mathrm{Cyr}^{-1}$, respectively. These values are well within range of independent, multi-model studies and observation-based estimates (Cramer et al., 2001; Takahashi et al., 2009). The spatial anthropogenic carbon uptake by the ocean simulated by the BCM-C is shown together with the observation-based estimates from Sabine et al. (2004) in Fig. 2. Here, we computed the anthropogenic carbon storage from the difference between carbon inventories in year 1994 and the averaged annual pre-industrial state. 


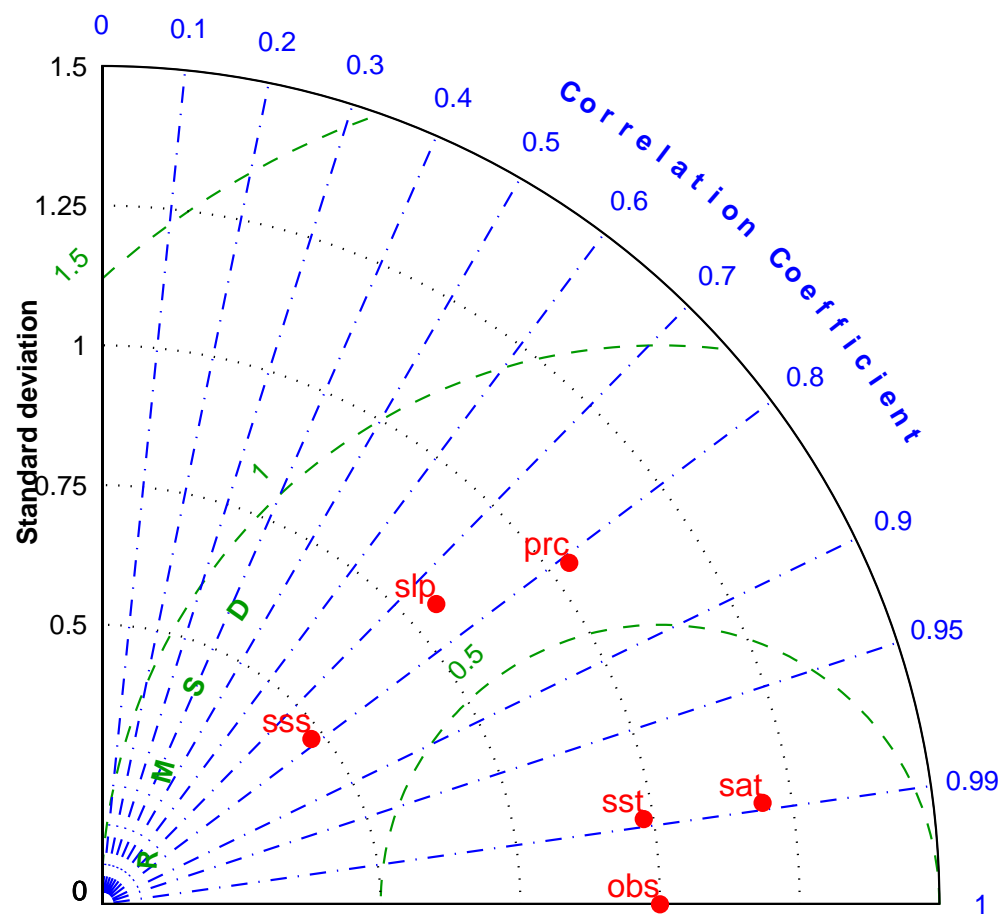

Fig. 1. Taylor diagram for annually-averaged sea surface temperature (sst), salinity (sss), surface air temperature (sat), precipitation (prc) and sea level pressure (slp) from the reference run (REF) as compared to climatology Levitus and NCEP reanalysis.
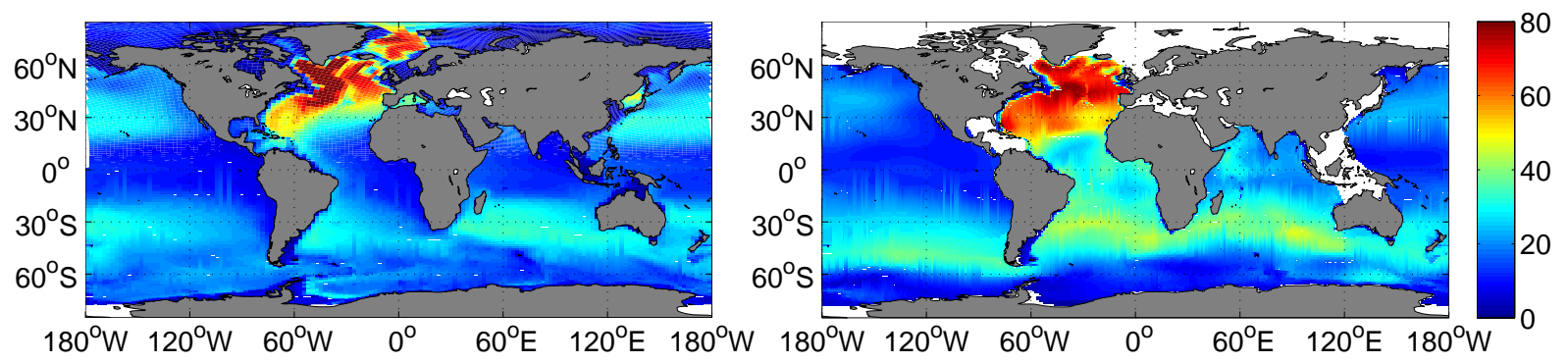

Fig. 2. Map of column integrated anthropogenic carbon content in the ocean for the year 1994 simulated by the BCM-C (left) and compared to the observation-based estimates (right) from Sabine et al. (2004). Units are in $\left[\mathrm{mol} \mathrm{C} \mathrm{m}^{-2}\right]$.

Globally, the time-integrated anthropogenic carbon uptake up to year 1994 is estimated to be $96 \mathrm{Pg} \mathrm{C}$. Of this amount, the North Atlantic region account for $21 \%$, whereas the regions south of $-14^{\circ} \mathrm{S}$ account for $47 \%$ of the global inventory. In general, the simulated regional anthropogenic carbon uptake is slightly stronger in the North Atlantic region along the Gulf Stream. This uncertainty may be attributed to the artificially large mixed-layer depth that allows surface carbon to be transported into deep ocean more efficiently (Assmann et al., 2010). This overestimation offsets the slightly lower carbon uptake in the rest of the world ocean regions. For the same period, the terrestrial counterpart takes up approximately $90 \mathrm{PgC}$. The values above are well within error ranges given in Sabine et al. (2004).
Figure 3 also shows that the BCM-C model reproduces the observed atmospheric $\mathrm{CO}_{2}$ concentrations relatively well (i.e., $382 \mathrm{ppm}$ for the present day value). In the COU simulation, the atmospheric $\mathrm{CO}_{2}$ concentration is projected to increase to $870 \mathrm{ppmv}$ by 2099 . This projection is well within the range given by 11 Earth system model forecasts, as shown in Fig. 3 (Friedlingstein et al., 2006).

Because the atmospheric $\mathrm{CO}_{2}$ change in the UNC simulations has no radiative effect, projected temperature variability remains within the pre-industrial state (see Fig. 4). In the COU simulation, the model projects an increase in global average surface atmosphere and ocean temperature by roughly $3.3^{\circ} \mathrm{C}$ and $2.5^{\circ} \mathrm{C}$, respectively as shown in Fig. 4 . Based on the changes in global surface atmosphere temperature, the climate sensitivity of the model, defined as the ratio 

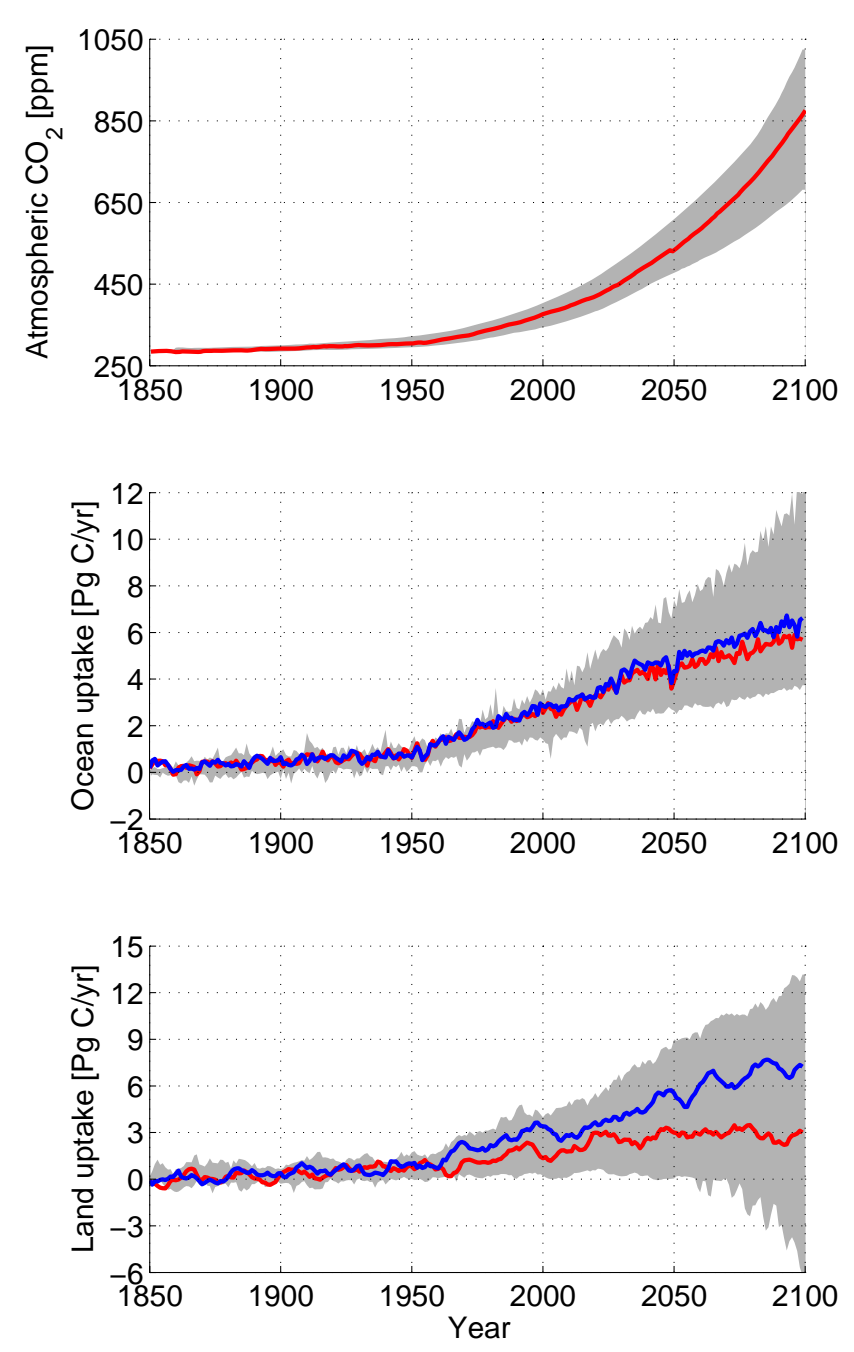

Fig. 3. BCM-C projection of annual (top) atmospheric $\mathrm{CO}_{2}$ concentration, (middle) oceanic carbon uptake and (bottom) terrestrial carbon uptake as compared to the range from other models (grey shading) (Friedlingstein et al., 2006). Red lines represent results from COU whereas blue lines represent results from UNC simulations.

of changes in global temperature to changes in atmospheric $\mathrm{CO}_{2}$, is $0.0056^{\circ} \mathrm{C} / \mathrm{ppm}$. This value is also within range of 0.0038-0.0082 ${ }^{\circ} \mathrm{C} / \mathrm{ppm}$ obtained from the other Earth system models (Friedlingstein et al., 2006).

Changes in global temperature, in turn, alter key features of the climate system, e.g., ocean circulation, sea-ice extent, precipitation, solar radiation and surface winds. These changes in fundamental climate parameters modify both the terrestrial and ocean carbon cycle, and finally feedback to atmospheric $\mathrm{CO}_{2}$ concentration and the climate system. To first order, an increase in global temperatures would reduce the average rate of carbon uptake by the terrestrial reservoir as well as the ocean.
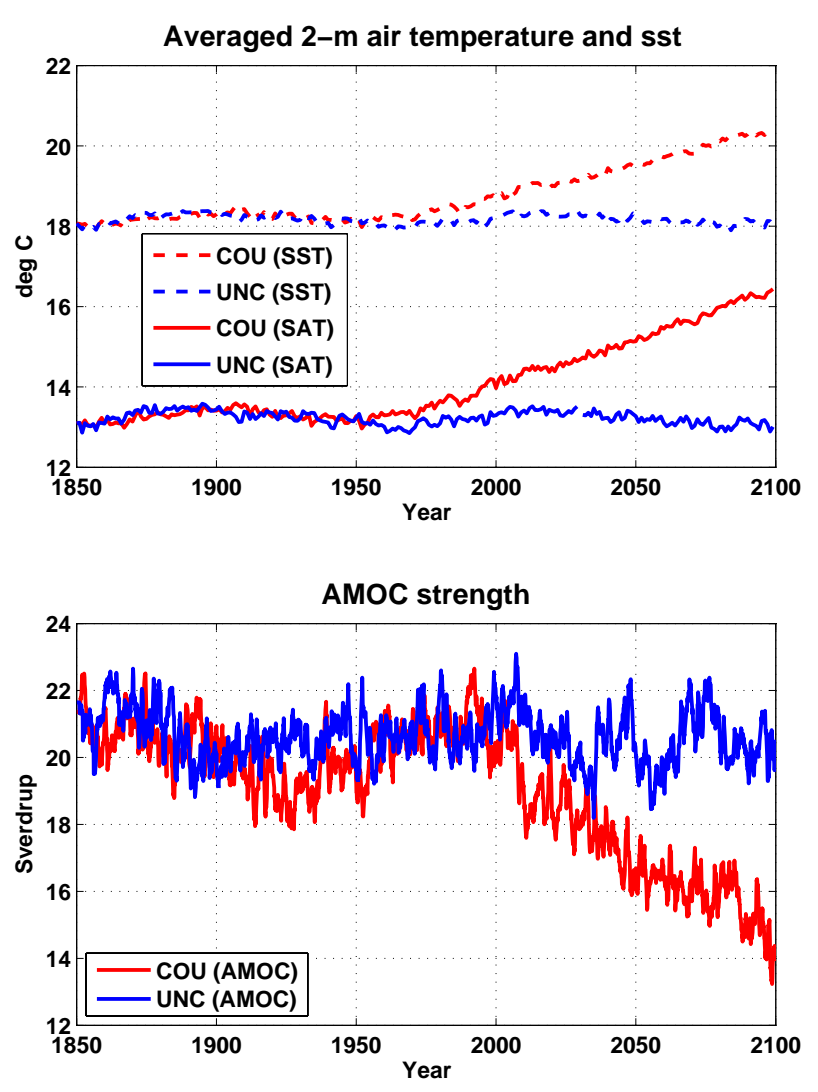

Fig. 4. Time-series of global mean (top) 2-m surface temperature and sea surface temperature and (bottom) strength of the Atlantic Meridional Overturning Circulation as projected by the BCM-C model for both the COU and UNC simulations. There are generally no significant trend changes in the UNC simulation because the changes in atmospheric $\mathrm{CO}_{2}$ concentration here have no radiative effect.

In both the COU and UNC experiments, Fig. 3 shows that the model simulates a continuous increase in atmospheric carbon uptake by the ocean, with annual uptake of $2.4 \mathrm{Pg} \mathrm{C} / \mathrm{yr}$ for the present-day climate and up to $6 \mathrm{Pg} \mathrm{C} / \mathrm{yr}$ uptake by year 2099. This increase in oceanic carbon uptake is expected as the difference between the partial pressure of $\mathrm{CO}_{2}$ in the atmosphere and ocean surface continues to increase. Nevertheless, the fraction of the annual $\mathrm{CO}_{2}$ emission taken up by the ocean decreases, implying that the ocean may be close to its carbon saturated state. In the COU simulation, the terrestrial carbon uptake reaches its maximum by the middle of the 21 st century with averaged annual uptake of nearly $3 \mathrm{Pg} \mathrm{C} / \mathrm{yr}$ and decreases slightly toward the end of this century. In the UNC simulation, where the climate change effect is suppressed, the terrestrial carbon uptake shows no significant decreasing trend, with maximum carbon uptake of roughly $7.5 \mathrm{Pg} \mathrm{C} / \mathrm{yr}$ by year 2099 . The significant difference 
in the terrestrial carbon uptake between the COU and UNC simulation suggests that the positive global climate-carbon cycle feedback is mainly attributed to terrestrial processes. Both the simulated annual ocean and terrestrical carbon uptakes look very reasonable, located well in the middle of other model estimates also shown in Fig. 3.

The COU simulations also show a reduction in the strength of the Atlantic Meridional Overturning Circulation (AMOC) from 21 to $14 \mathrm{~Sv}$ by year 2099 (see Fig. 4). This change is consistent with a multi-GCMs study by Schmittner et al. (2005) and resulted in only a small reduction in the marine primary production and export production, especially in the high latitude regions. Earlier studies show that the slow down in the overturning circulation may have little oceanic carbon cycle-climate feedback for the short-period pertinent to this study. For example, Zickfeld et al. (2008) summarize that up to 2100 , the increase in SST in the warmer climate, which reduces the $\mathrm{CO}_{2}$ solubility is mostly responsible for the reduction in the carbon uptake. Note that the increase in SST also decreases the $\mathrm{CO}_{2}$ buffer factor (i.e., buffer capacity increases with rising $\mathrm{T}$ ) for seawater.

For multi-century time scales, the AMOC and ocean circulation is generally found to be the main reason for reduced $\mathrm{CO}_{2}$ uptake. For these longer time scales, the weakening of the AMOC reduces the fluxes of upwelled nutrients to the surface, which in turn reduces the carbon uptake by the biological pump.

\subsection{Global climate-carbon cycle feedbacks}

We applied similar formulation used in the Friedlingstein et al. (2006) study to quantify both the global ocean and terrestrial climate-carbon feedbacks. Sensitivity of land/ocean carbon storage to changes in atmospheric $\mathrm{CO}_{2}$ concentration $\left(\beta_{\mathrm{L}} / \beta_{\mathrm{O}}\right)$ can be computed as follows:

$\beta_{\mathrm{O} / \mathrm{L}}=\frac{\Delta C_{\mathrm{O} / \mathrm{L}}^{\mathrm{unc}}}{\Delta C_{\mathrm{A}}^{\mathrm{unc}}}$,

where $\Delta C_{\mathrm{O} / \mathrm{L}}^{\mathrm{unc}}$ and $\Delta C_{\mathrm{A}}^{\mathrm{unc}}$ represent the change in carbon contents in the ocean/land and atmosphere, respectively, over a given simulation period in the UNC experiment. Figure 5a and $\mathrm{c}$ illustrate the evolution of $\beta_{\mathrm{O}}$ and $\beta_{\mathrm{L}}$ simulated by the BCM-C as compared to the other models. In both reservoirs, there are positive and relatively linear relationships between carbon uptake and increasing atmospheric $\mathrm{CO}_{2}$ concentration. For the ocean, Fig. 5a also shows that this relationship is nearly an overlap to the Max Planck Institute (MPI) models, in which they apply similar ocean carbon cycle model (i.e., HAMOCC5). This implies that the global sensitivity of the HAMOCC5 component with respect to atmospheric $\mathrm{CO}_{2}$ concentration is relatively robust, despite differences in physical forcing fields. For the land, these are noticeably spread in the sensitivities between the BCM-C as compared to other models that use the LPJ as the terrestrial component.
We attribute this variation to the regionally varying physical forcing fields, particularly temperature and precipitation. In Sect. 4.4, we also discuss how the variation in regional precipitation affects the regional sensitivity of carbon uptake to temperature.

Using the information from Eq. (1), we can estimate the sensitivity of ocean/land carbon uptake to change in climate $\left(\gamma_{\mathrm{L} / \mathrm{O}}\right)$, particularly surface temperature, by solving the following equation:

$\Delta C_{\mathrm{O} / \mathrm{L}}^{\mathrm{cou}}=\beta_{\mathrm{O} / \mathrm{L}} \Delta C_{\mathrm{A}}^{\mathrm{cou}}+\gamma_{\mathrm{O} / \mathrm{L}} \Delta T^{\mathrm{cou}}$,

where $\Delta T^{\text {cou }}$ represents the change in global mean surface temperature simulated in the COU simulation. Figure $5 \mathrm{~b}$ shows that the global oceanic carbon uptakes are negatively sensitive to changes in surface temperature, especially when the temperature change is greater than $2{ }^{\circ} \mathrm{C}$. Compared to the ocean sensitivity, the terrestrial carbon storage exhibits higher sensitivity (i.e., approximately double) to temperature change (see Fig. 5d). Although there is no clear signal, the sensitivity of carbon storage to temperature changes is relatively comparable for models with similar carbon cycle components (i.e., HAMOCC, LPJ).

For the year 2099, the sensitivities of ocean and land carbon storage to changes in atmospheric $\mathrm{CO}_{2}$ for the $\mathrm{BCM}$ $\mathrm{C}$ model is $1.0 \mathrm{Pg} \mathrm{Cppm}^{-1}$ and $1.5 \mathrm{PgCppm}^{-1}$, respectively. The respective mean values for the other models are $1.1 \pm 0.25$ (s.d.) and $1.4 \pm 0.58$ (s.d.) for both the ocean and land sensitivities. The sensitivities of ocean and land carbon uptake to changes in temperature are $-19 \mathrm{Pg} \mathrm{C} \mathrm{K}^{-1}$ and $118 \mathrm{Pg} \mathrm{C} \mathrm{K}^{-1}$ for the BCM-C model as compared to $-30 \pm 15$ (s.d.) and $-79 \pm 43.7$ (s.d.) for the mean from other models.

\subsection{Regional terrestrial climate-carbon cycle feedbacks}

All previous coupled climate-carbon cycle models reported in the literature unanimously demonstrate a positive feedback between terrestrial carbon cycle and climate change, mainly due to the consequences of kinetic sensitivity of photosynthesis and respiration to temperature (Luo, 2007). Figure $3 \mathrm{c}$ shows that the global terrestrial climate carbon cycle feedback simulated by our model is also positive, resulting in less uptake of approximately $323 \mathrm{Pg}$ carbon when climate change is taken into account in the COU simulation. On the other hand, when climate change is excluded (i.e., in UNC simulation), the $\mathrm{CO}_{2}$ fertilization effect dominates the simulated steady increase in the terrestrial carbon uptake. The feedback strength in the model is controlled primarily by the response of terrestrial photosynthesis and respiration to changes in different climate variables, such as temperature and atmospheric $\mathrm{CO}_{2}$ concentration. Here, we will assess the regional strength of the terrestrial climate carbon cycle feedback by computing the sensitivity of regional carbon uptake, net primary production, and respiration dynamics to changes in atmospheric $\mathrm{CO}_{2}$ concentration as well as surface temperature. 

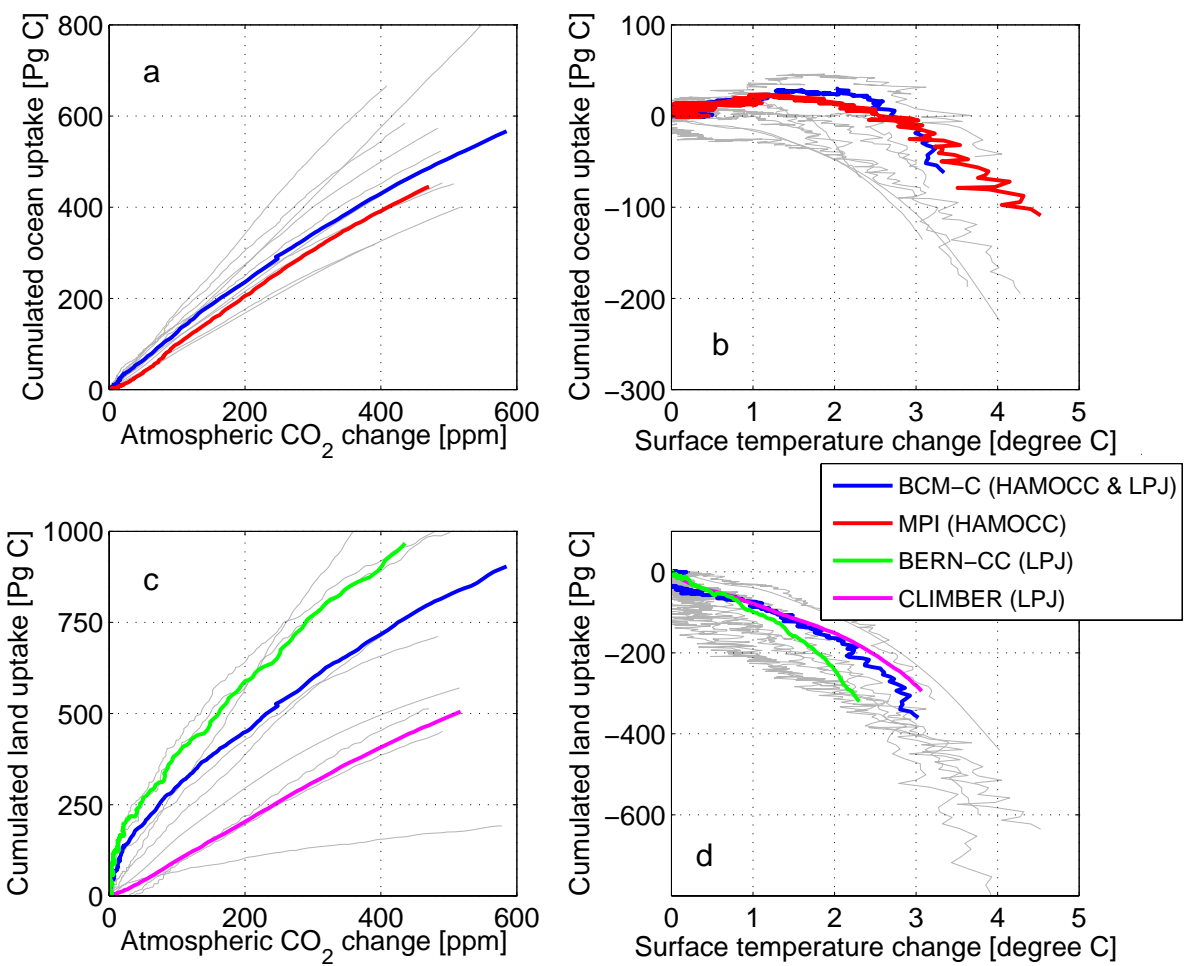

Fig. 5. The sensitivity of the (a, b) oceanic carbon uptake to change in atmospheric $\mathrm{CO}_{2}$ concentration and surface temperature and (c, d) terrestrial carbon uptake to change in atmospheric $\mathrm{CO}_{2}$ and surface temperature. Also plotted here are similar sensitivities of the other Earth system models (light-grey lines) and models with similar carbon cycle components: MPI (Max Planck Institute, red lines), BERN-CC (Bern Carbon-Cycle Climate model, green lines), and CLIMBER (CLIMBER2-LPJ, purple lines).

While an increase in atmospheric $\mathrm{CO}_{2}$ would generally amplify terrestrial carbon uptake due to $\mathrm{CO}_{2}$ fertilization, the associated climate change effect on regional terrestrial carbon cycle is less understood and predictable. The geographical distribution of time-integrated terrestrial carbon uptake by year 2099 from the COU experiment is shown in Fig. 6a. By the end of the century, regions that remain prominent net carbon sinks are the equatorial regions, central and northern Asia, central Europe, and northern America. In the tropics, significant carbon uptake is mainly attributed to an increase in atmospheric $\mathrm{CO}_{2}$ due to the fertilization effect. At high latitudes, in addition to $\mathrm{CO}_{2}$ fertilization, an extended growing season also leads to an increase in NPP. However, in certain regions (i.e., northeastern Europe, northern and central America, and eastern Asia), where winter temperatures increase significantly by as much as $20^{\circ} \mathrm{C}$, soil respiration overcomes the NPP increase, resulting in a reduced soil turnover time. In these regions, the model simulates outgassing of carbon to the atmosphere by the end of the 21 st century.

Figure $6 \mathrm{~b}$ shows the difference in accumulated carbon uptake between the COU and UNC simulations. To first order, regions with negative values represent regions with positive climate-carbon cycle feedback. Some regions, such as the equatorial Africa, Amazonia, and southeastern Australia, take up carbon initially in the early simulation periods, but end up releasing more carbon by the end of the 21 st century. The main reason for the outgassing of the tropical regions mentioned above is the reduction in NPP due to warming (see the regional sensitivity of NPP to temperature change in Fig. 7). This sensitivity is in line with study by Sitch et al. (2008). Figure $6 \mathrm{~b}$ also shows that there are a few temperate terrestrial biosphere domains along the $30^{\circ} \mathrm{N}$ and $20^{\circ} \mathrm{S}$ that take up more carbon when climate change is included in the model simulations.

For the regional sensitivity of carbon uptake to atmospheric $\mathrm{CO}_{2}$, we applied a similar formulation as Eq. (1). Here the sensitivity is computed for different latitudinal bands and weighted by the surface area. The latitudinal evolution of $\beta_{\mathrm{L}}$ is shown in Fig. 7a. It shows that the response of carbon uptake due to increase in atmospheric $\mathrm{CO}_{2}$ alone is generally strongest in the equatorial regions and decreasing toward higher latitude regions. Since carbon uptake in our model is computed mainly as the difference between NPP and respiration, the sensitivities of these terms to $\mathrm{CO}_{2}$ concentration are also computed. Generally, Fig. $7 \mathrm{~b}$ also shows that NPP at low latitudes has the strongest $\mathrm{CO}_{2}$ fertilization effect. The sensitivity variation between different latitudes is to some extent contributed by temperature variabilities. The study by Farquhar et al. (1980) demonstrates that the 

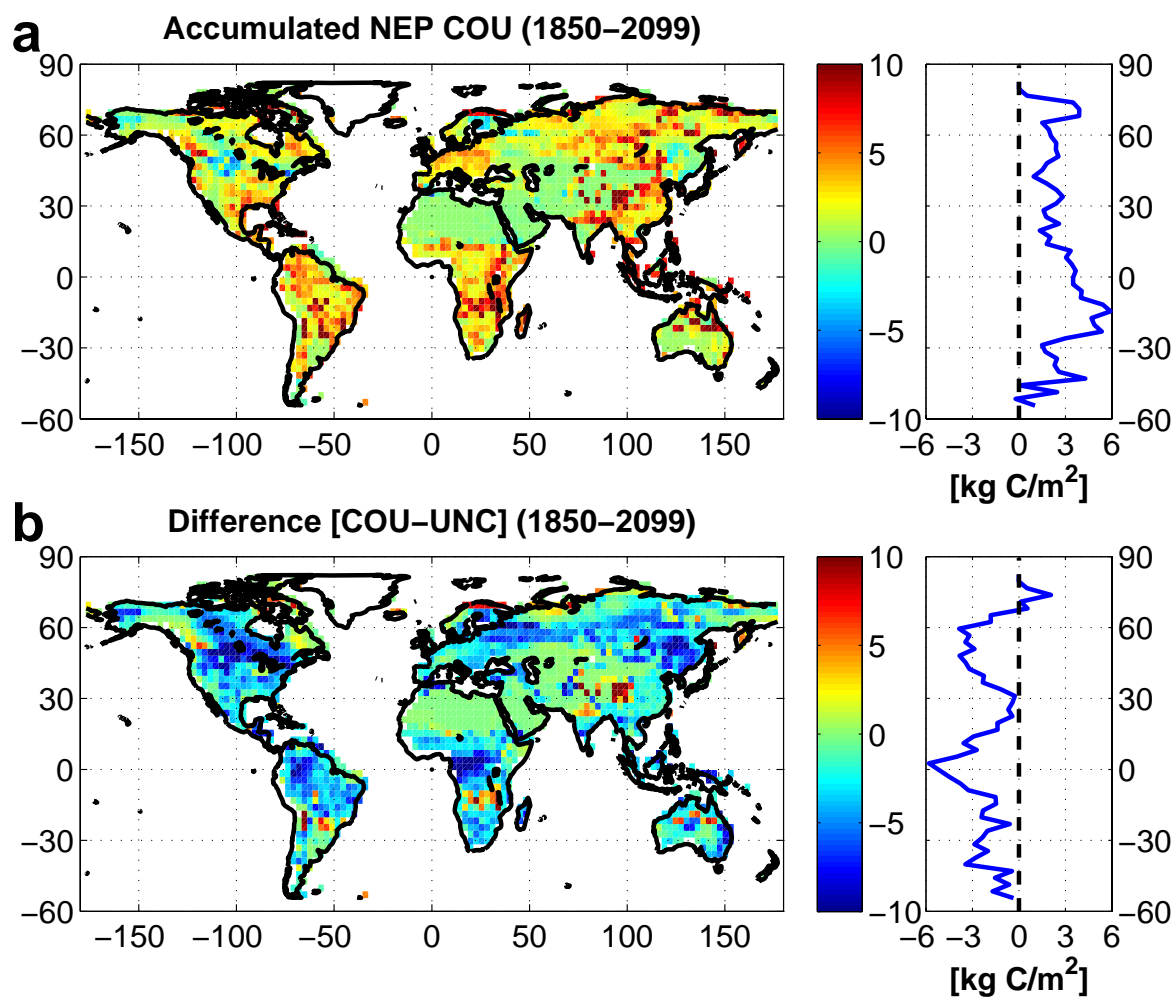

Fig. 6. Geographical distribution of accumulated carbon uptake by the land [Pg C] (top) simulated by the COU simulation and (bottom) the difference between COU and UNC simulations. The right panel shows the latitudinal average of carbon uptake $\left[\mathrm{kg} \mathrm{C} / \mathrm{m}^{2}\right]$.

assimilation rate of $\mathrm{CO}_{2}$ is more efficient in warmer temperatures. Analogously, Hickler et al. (2008) show that the effect of $\mathrm{CO}_{2}$ enhancement on regional plant photosynthesis is strongest at higher temperature regions.

Interestingly, the latitudinal response of soil respiration to $\mathrm{CO}_{2}$ changes (i.e., Fig. $7 \mathrm{c}$ ) is very similar to the response of NPP where that higher ambient $\mathrm{CO}_{2}$ concentrations lead to higher soil respiration rates. The effect of $\mathrm{CO}_{2}$ fertilization on heterotrophic respiration can be explained as follows. Higher atmospheric $\mathrm{CO}_{2}$ levels reduce stomatal opening and, hence, reduce evapotranspiration. This condition leads to the increase in water usage efficiency and increasing soil-water moisture. In addition, the increase in NPP also leads to an increase in litter input to the soil in some regions. Finally, these factors lead to an increase in soil respiration. In the low latitudes, the strong sensitivity simulated by the model is mainly due to the warm tropical temperatures and significant increase in soil moisture. At high latitudes, despite an increase in litter carbon as well as soil moisture, the soil decomposition remains low in the high $\mathrm{CO}_{2}$ environment, which may be due to the lower temperature.

In order to analyse the sensitivity of regional carbon uptake to changes in temperature alone, an additional experiment (UNCb) was performed by only running the LPJ model off-line. In this experiment, the LPJ is simulated for the same period (1850-2099), forced by the climate variability from the COU simulation while maintaining constant, pre-industrial atmospheric $\mathrm{CO}_{2}$ concentration. Here, the sensitivity of land carbon uptake to changes in temperature can be computed as:

$\gamma_{\mathrm{L}}=\frac{\Delta C_{\mathrm{L}}^{\mathrm{uncb}}}{\Delta T^{\mathrm{cou}}}$,

where $\Delta C_{\mathrm{L}}^{\mathrm{uncb}}$ and $\Delta T^{\mathrm{cou}}$ represent the change in land carbon contents in the UNCb and change in surface temperature in the COU simulations, respectively. All regions show uniform sensitivity signs, increase in carbon outgassing with higher atmospheric temperature. Figure $7 d$ shows that tropical regions have highest sensitivity towards changes in temperature, whereas the high latitude regions generally have lower sensitivity. In the northern hemisphere mid-latitude $\left(30^{\circ} \mathrm{N}-60^{\circ} \mathrm{N}\right)$, our simulation also shows relatively large climate-carbon cycle feedback, where future warming leads to a reduction in the annual NPP and an increase in heterotrophic respiration. This result is in line with independent study of Cramer et al. (2001), which uses multiple dynamical vegetation models to assess the terrestrial climate-carbon cycle feedback.

In general, higher temperatures affect the tropical regions by decreasing the annual NPP and have relatively small influence on the heterotrophic respiration. At high latitudes, 

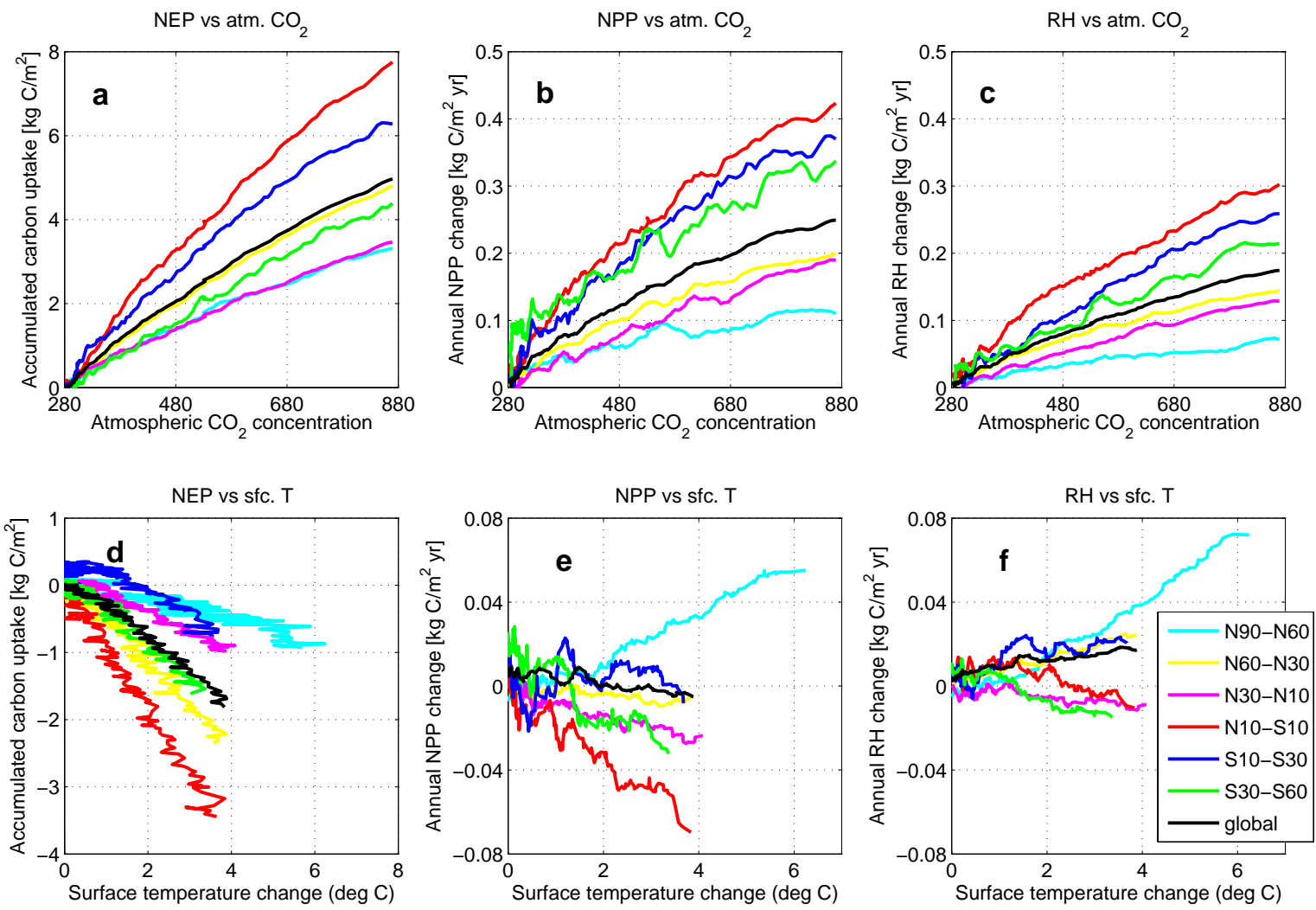

Fig. 7. Latitudinal sensitivities of (a) cumulated land carbon uptake to atmospheric $\mathrm{CO}_{2}$ concentration, (b) sensitivity of annual terrestrial NPP to changes in atmospheric $\mathrm{CO}_{2}$, and (c) sensitivity of heterotrophic respiration to changes in atmospheric $\mathrm{CO}_{2}$. Bottom figures (d, e, and f) shows similar sensitivities to changes in surface temperature.

increase in soil respiration due to warming overtakes the increase in NPP due to the extended growing seasons. This mechanism would eventually lead to a significant reduction in the soil carbon turnover time by up to 25 years (not shown here) in these regions. Figure $7 \mathrm{e}$ and $\mathrm{f}$ also show that the regional sensitivity of net primary production and heterothropic respiration to changes in temperature is very nonlinear. We attribute this non-monotic sensitivity to variabilities of other physical forcings (i.e., precipitation) induced by changes in temperature. For example, Supplemental Fig. 5 shows that for some regions (e.g., N90-N60), the changes in temperature is relatively linear to change in precipitation. In other regions, there is no clear relationship between regional changes in temperature and precipitation.

\subsection{Regional ocean climate-carbon cycle feedback}

The regional oceanic carbon uptake is determined by the gradient between the partial pressure of $\mathrm{CO}_{2}$ in the atmosphere and surface ocean, where the latter term depends strongly on the physical state of the ocean, hence the climate variability. As a first step to analyse the regional climate-carbon cycle feedback in the ocean, we compute the carbon uptake changes with respect to the pre-industrial state, and compute the difference between the COU and UNC simulations. Figure $8 \mathrm{a}$ shows a map of time-integrated changes (1860-2099) in oceanic carbon uptake relative to the average pre-industrial (i.e., 1850-1859) state. It gives estimates of regional accumulated anthropogenic carbon uptake for the experimental period. In both model runs, the model simulates a net anthropogenic carbon uptake in nearly all ocean regions as a result of enhanced atmospheric $\mathrm{CO}_{2}$ concentration. The oceanic carbon uptake through the end of the 21 st century occurs mainly in the North Atlantic, northwestern Pacific and in the Southern Ocean (South of $30^{\circ} \mathrm{S}$ ). In these regions, substantial carbon fluxes into the ocean correspond to regions with pronounced winter mixing, which is an important mechanism to transport surface DIC to a deeper ocean layer. Additionally, relative to the pre-industrial state, the COU simulation generates the largest changes in carbon fluxes in the Southern Ocean, where the anomaly of carbon uptake is as high as $10 \mathrm{~kg} \mathrm{C} / \mathrm{m}^{2}$ over the entire model integration period (see Fig. 8a).

The difference between the COU and UNC simulations in the accumulated carbon fluxes to the ocean are shown in Fig. 8b. Negative values represent less carbon uptake when climate change is taken into account, whereas positive values represent the opposite. Negative patterns appear in the 
Southern Ocean (between $30^{\circ} \mathrm{S}$ and $50^{\circ} \mathrm{S}$ ), North Atlantic and parts of northwestern Pacific regions. Positive values are most pronounced in the high-latitude Southern Ocean, the Arctic regions, southeast Australia and in the western boundary currents along the North Pacific.

\subsubsection{Temporal climate change impact on regional air-sea $\mathrm{CO}_{2}$ fluxes}

Figure $8 \mathrm{~b}$ also shows that the impact of climate change on regional $\mathrm{CO}_{2}$ fluxes is spatially inhomogeneous. In order to analyse the temporal impact of climate change on regional carbon uptake, we compute the difference (COU-UNC) in spatially-integrated annual carbon uptake (shown in Fig. 9).

Except for the high latitude Southern Ocean, the effect of climate change in all other regions is generally not pronounced until the early 21 st century. Less anthropogenic carbon uptakes are simulated when climate change is included, predominantly in the Atlantic Ocean basin and in the Tropical and North Pacific Oceans. By 2099, in parts of the Atlantic Ocean, the model indicates a reduction of more than $0.2 \mathrm{Pg} \mathrm{yr}^{-1}$ of anthropogenic carbon uptake, partly attributed to climate change. These negative changes (i.e., COU-UNC) in anthropogenic carbon uptake suggest positive climatecarbon cycle feedback mechanisms acting in most of the ocean regions. Nevertheless, Fig. 9 clearly indicates that the feedback strength could vary considerably from one region to another. In both polar regions (i.e., ARC and SOC), the COU simulates more carbon uptake than the UNC. This pattern implies that climate change increases the anthropogenic carbon uptake in these polar regions, particularly attributed to the sea ice retreat. By the end of the 21st century, the Southern Ocean would take up roughly $\sim 0.15 \mathrm{PgC} \mathrm{yr}^{-1}$ more when climate change is included in the model simulation. We note that the BCM-C model generates biases due to stronger mixing in this region, allowing the sea ice to almost disappear in the summer period. Figure 10 shows that most of the difference between carbon uptake in the COU and UNC simulations occurs within or close to the areas where the sea ice has retreated. The retreat of sea ice due to melting allows an additional uptake of approximately $20 \mathrm{Pg}$ carbon between years 2000 and 2099.

\subsubsection{Climate impact on regional $\mathrm{CO}_{2}$ flux determining properties}

In the next step, we analysed how regional climate change alters the oceanic carbon uptake mechanisms simulated in the BCM-C, particularly toward the end of the experimental periods. In the model, the flux of carbon between the atmosphere and the ocean interface is defined as follows:

$F_{\mathrm{CO}_{2}}=\alpha \cdot K \cdot \Delta p \mathrm{CO}_{2}$,

where $\alpha$ is the solubility of $\mathrm{CO}_{2}$ gas in seawater computed as a function of seawater temperature and salinity according to
Weiss (1974), $K$ is the gas transfer velocity, which depends on the surface wind speed and the Schmidt number according to Wanninkhof (1992) and $\triangle p \mathrm{CO}_{2}$ is the difference in partial pressure of $\mathrm{CO}_{2}$ between the atmosphere and the ocean. In the model, solubility of gaseous $\mathrm{CO}_{2}$ in seawater is predominantly determined by SST and secondarily by surface salinity, where higher SST and higher salinity both lead to lower solubility. In contrast, lower SST and lower salinity lead to higher solubility. The $\mathrm{CO}_{2}$ gas transfer velocity in the model is mainly proportional to the fraction of sea-ice coverage and the square of surface wind speed, but it also depends on the SST. Thus, higher wind speeds and lower surface temperatures lead to a faster transfer rate of $\mathrm{CO}_{2}$ gas into or out of the ocean.

To first order, climate change (i.e., warming) affects the solubility and gas transfer rate. We computed the comparative change of these parameters (for the period 2080-2099) relative to the pre-industrial period (i.e., 1850-1869) for the COU simulations. Figure 11a shows that climate change reduces the solubility in virtually all ocean regions. The largest reduction occurs within the high latitude oceans, where the solubility is reduced by approximately $20 \%$, relative to the pre-industrial state. In parts of the North Atlantic sub-polar gyre, there is a slight increase in solubility due to the SST cooling in this region. Figure 11b shows that future climate change increases the gas transfer rate notably in the model, particularly in the polar regions. Here, the gas transfer rate increases by more than $100 \%$ due to the retreat in sea-ice. While solubility reduction leads to the decrease in carbon uptake, increase in gas transfer rate increases the carbon exchange across the air-sea interface. For the UNC simulation, there is no significant change in the solubility and gas transfer rate. Both COU and UNC simulations generally yield similar spatial change in $\triangle p \mathrm{CO}_{2}$ component of Eq. (4), as both simulations apply the same atmospheric $\mathrm{CO}_{2}$ concentration.

To quantitatively estimate how changes in each of the above parameters affect the regional carbon uptake, we applied the similar method used by Crueger et al. (2008). Following their study, differences in carbon uptake simulated by the COU and UNC can be approximately separated into differences due to solubility, gas transfer rate, and $\Delta p \mathrm{CO}_{2}$ variation:

$\Delta F_{\mathrm{CO}_{2}(\mathrm{COU}-\mathrm{UNC})} \approx \Delta F_{\alpha}+\Delta F_{K}+\Delta F_{\Delta p \mathrm{CO}_{2}}$,

where $\Delta F_{\alpha}, \Delta F_{K}$, and $\Delta F_{\Delta p \mathrm{CO}_{2}}$ can be estimated as follows:

$$
\begin{aligned}
& \Delta F_{\alpha}=\Delta \alpha \cdot \bar{K} \cdot \overline{\Delta p \mathrm{CO}_{2}}, \\
& \Delta F_{K}=\bar{\alpha} \cdot \Delta K \cdot \overline{\Delta p \mathrm{CO}_{2}}, \\
& \Delta F_{\Delta p \mathrm{CO}_{2}}=\bar{\alpha} \cdot \bar{K} \cdot \Delta\left(\Delta p \mathrm{CO}_{2}\right) .
\end{aligned}
$$

In the above equations, " $\Delta$ " represents the difference and "-" represents the mean of the denoted terms from the COU and UNC simulations. Here, the post-processing computations 
a

Integrated air-sea $\mathrm{CO}_{2}$ flux (1860-2099)

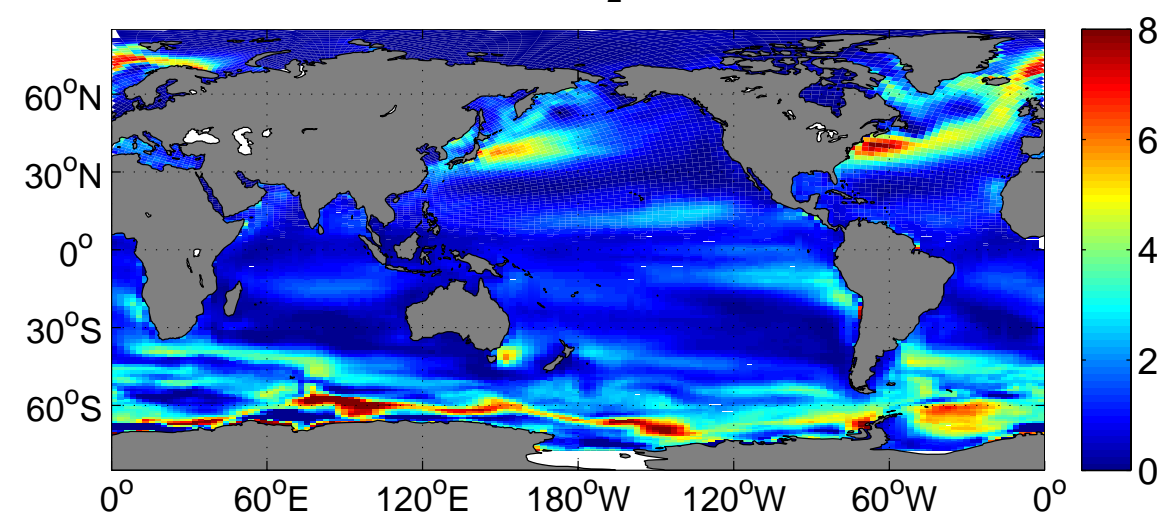

b Difference (COU-UNC) in integrated air-sea $\mathrm{CO}_{2}$ flux

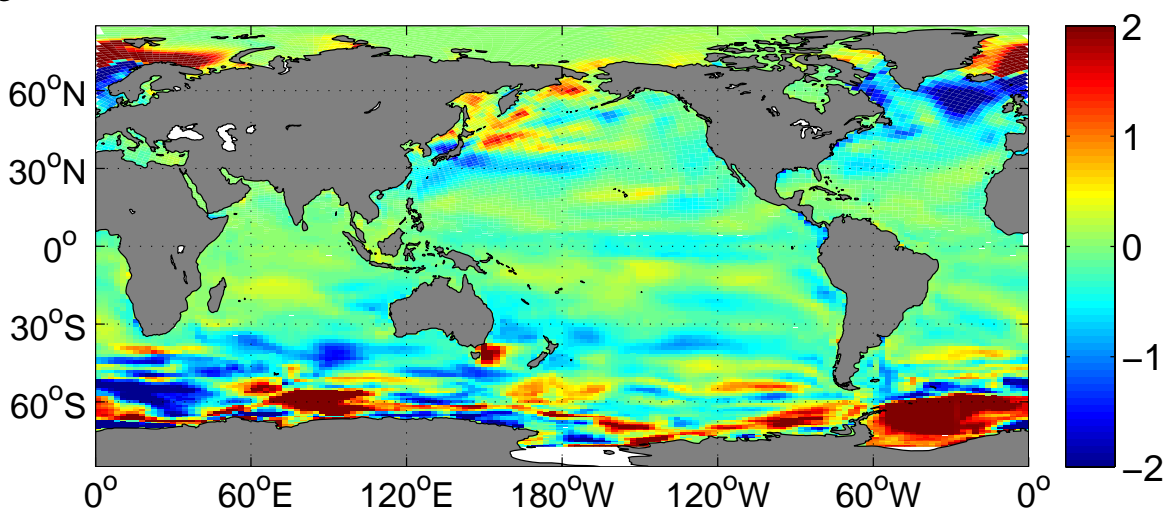

Fig. 8. Map of (top) time-integrated (1860-2099) changes in carbon uptake relative to the pre-industrial period (1850-1859) from the COU simulations and (bottom) the difference between the fully coupled and the uncoupled simulations (COU-UNC). Units are in $\left[\mathrm{kg} \mathrm{C} / \mathrm{m}^{2}\right]$

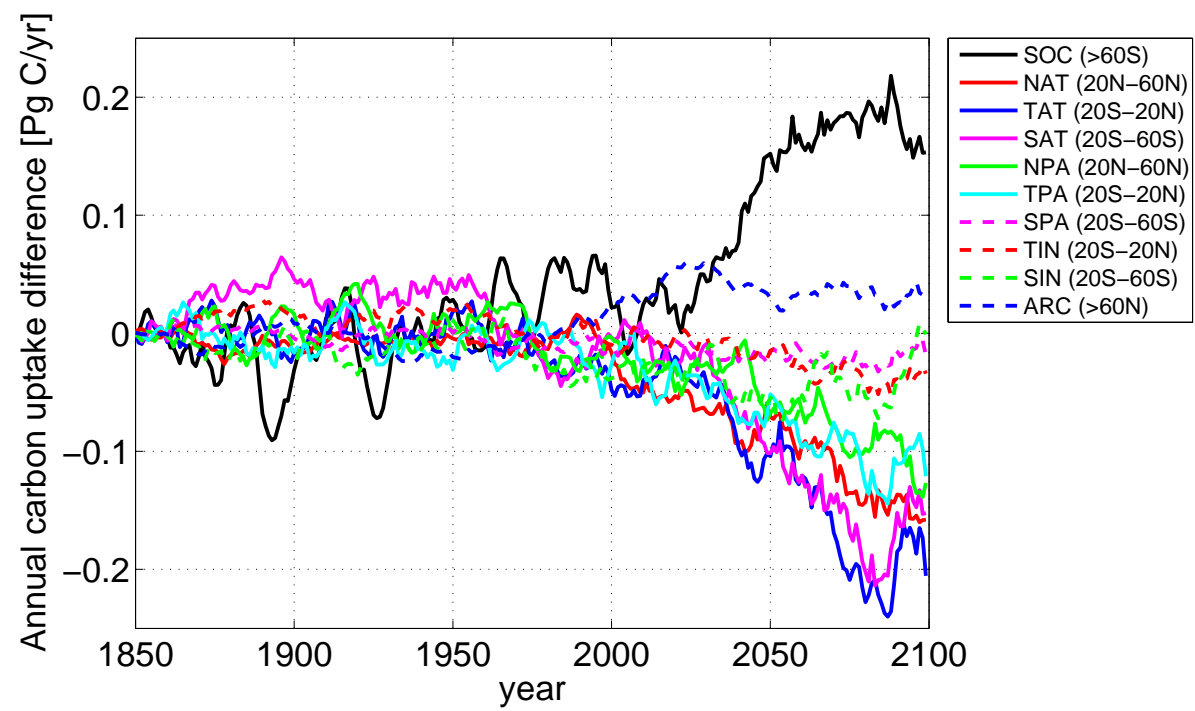

Fig. 9. Coupled minus uncoupled (COU-UNC) of spatially-integrated annual oceanic carbon uptake (10-year running mean). Regions are defined as follow: Southern Ocean (SOC), North Atlantic (NAT), Tropical Atlantic (TAT), South Atlantic (SAT), North Pacific (NPA), Tropical Pacific (TPA), South Pacific (SPA), Tropical Indian (TIN), South Indian (SIN), and Arctic (ARC). 


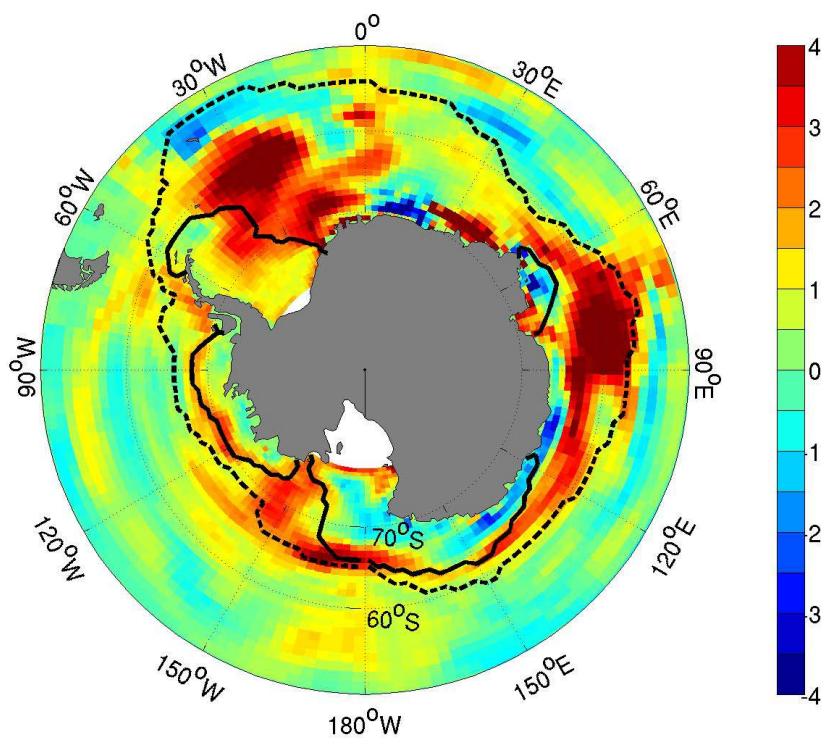

Fig. 10. Changes in atmospheric carbon uptake (similar to Fig. 8b) for the Southern Ocean together with average winter (January 2070-2099) sea-ice extent for the (solid black line) COU and (dashed black line) UNC simulations. Unit of colour shades are in $\left[\mathrm{kg} \mathrm{C} / \mathrm{m}^{2}\right]$
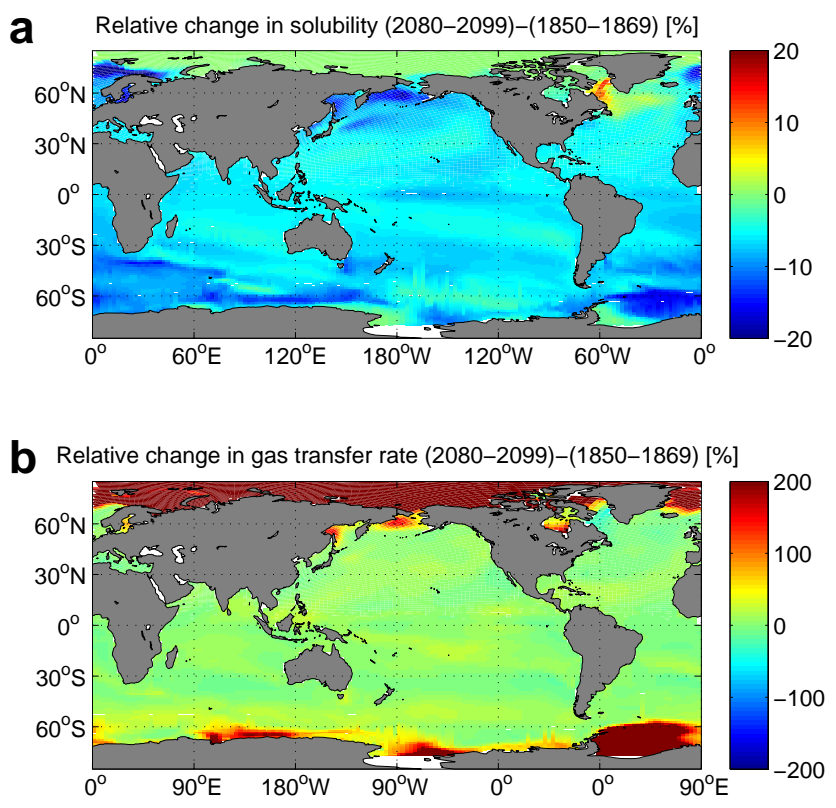

Fig. 11. Change in $\mathrm{CO}_{2}$ gas solubility and gas transfer rate for the 2080-2099 period relative to the pre-industrial period simulated in the COU. Units are in [\%].

are performed for the difference and average for the period of 2080-2099, since the largest changes between the two simulations occur within this period (see also Fig. 9). Figure 12 shows the map of changes of oceanic carbon uptake attributed to these different terms (based on Eqs. 6, 7, and
8) together with the actual difference of simulated carbon uptake between the two runs (i.e., left-hand side of Eq. 5). Positive values represent more carbon uptake when climate change is taken into consideration, whereas negative values represent less carbon uptake with climate change.

While the model simulates global warming of SST by approximately $2.5^{\circ} \mathrm{C}$, most of this warming occurs within high latitude regions (i.e., Southern Ocean, northwest Pacific, North Atlantic, and the Arctic), which leads to a reduction of $\mathrm{CO}_{2}$ solubility. In contrast, in the North Atlantic near Greenland, there is a slight increase of solubility due to SST cooling. An earlier study, such as Mikolajewicz et al. (2007) also produced similar cooling in their future model simulation. We attribute this cooling of SST to the potential reduction of lateral heat fluxes from the warm subtropical water in connection to the slowdown of AMOC strength. In the Southern Ocean, the reduction in the solubility pattern also reflects a pattern of SST increase caused by climate change. Maximum SST increases by as much as $5{ }^{\circ} \mathrm{C}$ are simulated along latitude $60^{\circ} \mathrm{S}$ of the Indian and Atlantic Ocean sections. Consequently, we see similar patterns in the reduction of carbon uptake due to lower solubility (see Fig. 12a). Consistent with the study by Crueger et al. (2008), our model produces smaller changes in surface solubility in the Equatorial Pacific, despite a regional sea surface warming of up to $3{ }^{\circ} \mathrm{C}$. To confirm this, we performed a simple back-of-theenvelope calculation of $\mathrm{CO}_{2}$ gas solubility (Weiss, 1974) in seawater using mean SST and SSS for the period 2080-2099 $\left(29.4^{\circ} \mathrm{C}, 34.5 \mathrm{psu}\right)$ as compared to the pre-industrial period $\left(26.8^{\circ} \mathrm{C}, 34.6 \mathrm{psu}\right)$. The calculation yielded a reduction of solubility from 0.0278 to 0.0262 moles $\mathrm{L}^{-1} \mathrm{ppm}^{-1}$. This relatively small change in solubility is due to the fact that the solubility changes are less significant in warmer than colder environments (Weiss, 1974).

An increase in carbon uptake due to increased gas transfer velocities predominantly occurs in the Southern Ocean along the $60^{\circ} \mathrm{S}$ latitude band. Whilst there is an increase (i.e., by approximately $30 \%$ ) in the zonal average near surface wind speed along $60^{\circ} \mathrm{S}$ latitude, a significant increase in gas transfer velocity is mainly attributed to the retreat of the average sea ice from approximately $55^{\circ} \mathrm{S}$ to $>60^{\circ} \mathrm{S}$ (see also Fig. 10). Also note that the HAMOCC5.1 model treats sea ice as an impermeable lid, thus, the fraction of sea ice in the model grid is a determining factor for air-sea gas exchange. Over the North Atlantic sub-polar gyre, there is a small reduction in wind stress, which slightly reduces the carbon uptake in this region as shown in Fig. $12 \mathrm{~b}$.

Despite large spatial variabilities in the factors determining regional carbon uptake mechanism, Fig. $12 \mathrm{c}$ and d show that differences in carbon uptake between the COU and UNC simulations mainly resemble the effect of changes in partial pressure $\mathrm{CO}_{2}$ difference between the atmosphere and the ocean. Since the atmospheric $\mathrm{CO}_{2}$ concentration in the model is represented as a bulk annual averaged value, the spatial variability in $\Delta p \mathrm{CO}_{2}$ is simply determined by the 


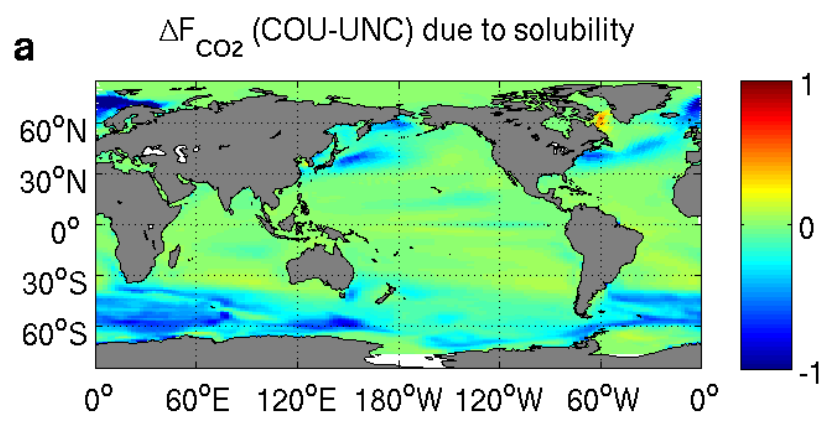

b $\Delta \mathrm{F}_{\mathrm{CO} 2}$ (COU-UNC) due to gas transfer rate

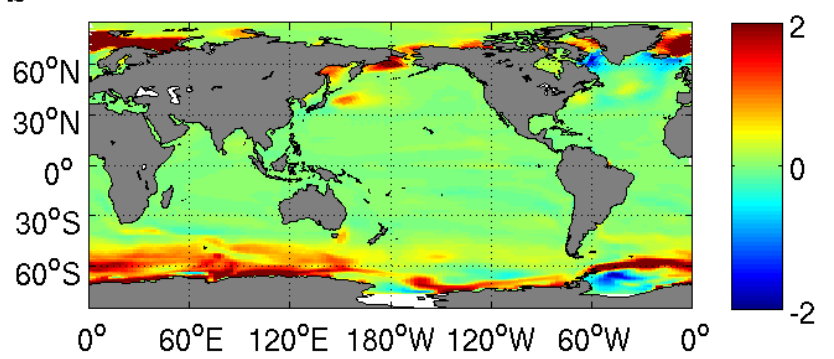

c $\quad \Delta \mathrm{F}_{\mathrm{CO} 2}(\mathrm{COU}-\mathrm{UNC})$ due to $\triangle \mathrm{pCO}_{2}$
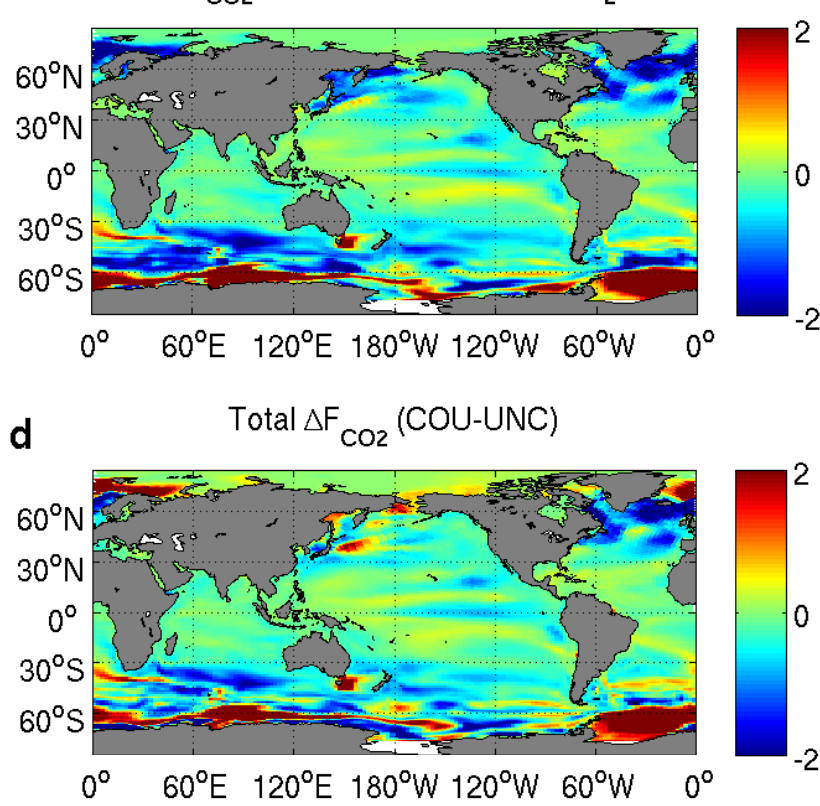

Fig. 12. Differences in oceanic carbon uptake between the COU and UNC (2080-2099) due to the (a) solubility, (b) gas transfer velocity, (c) difference in partial pressure of $\mathrm{CO}_{2}$ effects, and the (d) total simulated carbon uptake difference. Units are in [moles $\mathrm{C} \mathrm{m}^{-2} \mathrm{yr}^{-1}$ ]. Positive values represent more carbon uptake when climate change is taken into consideration, whereas negative values represent the opposite.

spatial surface ocean $p \mathrm{CO}_{2}$ pattern. Surface $p \mathrm{CO}_{2}$ in the model is controlled by surface DIC, alkalinity, salinity and temperature. The surface DIC concentration is, in turn, deter-
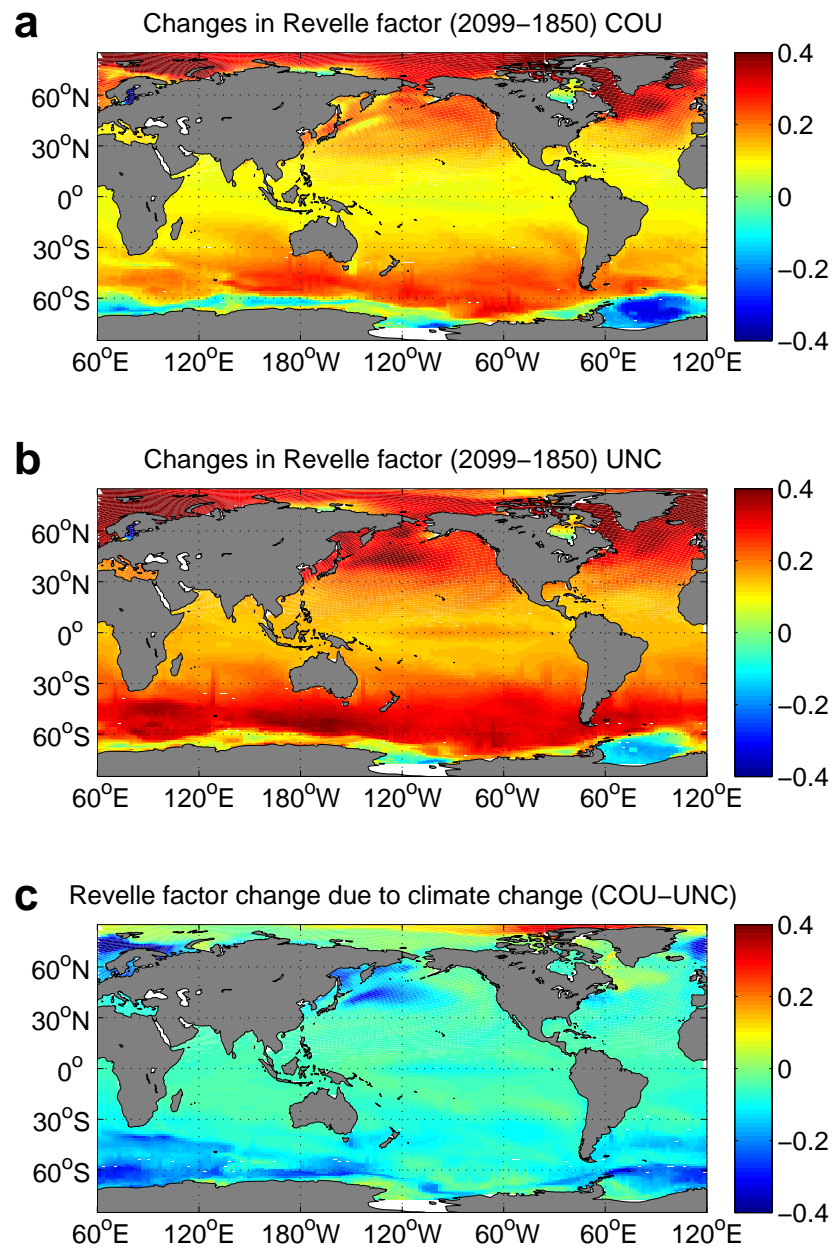

Fig. 13. Difference in Revelle factors between year 2099 and 1850 simulated in the (a) COU and (b) UNC simulations, and (c) COU minus UNC for year 2099.

mined by regionally and temporally varying biophysical processes such as the ocean circulation, biological activity and convective mixing (Tjiputra and Winguth, 2008). In large portions of the low-latitude regions $\left(30^{\circ} \mathrm{N}-30^{\circ} \mathrm{S}\right)$, there is little difference in the $\Delta p \mathrm{CO}_{2}$ between the $\mathrm{COU}$ and $\mathrm{UNC}$ simulations. This suggests relatively small differences in the low-latitude ocean circulation and biological activity simulated in the COU and UNC. In the North Atlantic (between $30^{\circ} \mathrm{N}-60^{\circ} \mathrm{N}$ ), the $\Delta p \mathrm{CO}_{2}$ simulated in the $\mathrm{COU}$ run is lower than that of the UNC run. This difference is potentially due to weaker winter mixing processes (i.e., the average mixedlayer depth decreases by as much as $100 \mathrm{~m}$ in the simulation with climate change), which is the dominant mechanism for transporting $\mathrm{CO}_{2}$ from the surface to the deep ocean and maintaining lower surface DIC concentrations. In the North Pacific, noticeably lower carbon uptake due to lower $\Delta p \mathrm{CO}_{2}$ is simulated in COU. In contrast to the North Atlantic, the changes in mixed-layer depth signals in this region are insignificant. Therefore, the $4^{\circ} \mathrm{C}$ warmer SST may 
be the reason for lower $\Delta p \mathrm{CO}_{2}$ simulated in COU. Note that warmer SSTs would yield higher partial pressures of $\mathrm{CO}_{2}$ despite similar surface DIC concentrations. Warming over the Southern Ocean between $30^{\circ} \mathrm{S}$ and $60^{\circ} \mathrm{S}$ lowers the average mixed-layer depth and increases the surface $p \mathrm{CO}_{2}$ in the COU. However, in regions where the warming causes the sea-ice cover to disappear (South of $60^{\circ} \mathrm{S}$ ), the model simulates an increase of the average mixed layer depth, by as much as $100 \mathrm{~m}$, as compared to the simulation without climate change.

In terms of the global carbon budget, Fig. 12 also indicates that the consequences of climate change in the air-sea $\mathrm{CO}_{2}$ flux determining terms in the model are of the same order of magnitude. This suggests that the climate induced changes in $\mathrm{CO}_{2}$ solubility, gas transfer rate, as well as $\Delta p \mathrm{CO}_{2}$ are of equal importance in regulating the feedback mechanism.

\subsubsection{Changes in regional Revelle factor}

The above analysis shows that warming will reduce the solubility of $\mathrm{CO}_{2}$ gas in seawater. However, we note that changes in SST and $p \mathrm{CO}_{2}$ will influence the Revelle factor. The Revelle factor measures the changes of partial pressure of $\mathrm{CO}_{2}$ in seawater for a given change in DIC. Hence, for a given increase in atmospheric $\mathrm{CO}_{2}$ concentration, ocean waters with low values of the Revelle factor have higher oceanic equilibrium concentration of DIC than ocean waters with a high Revelle factor (Sabine et al., 2004). In this study, the simulated increase in water temperature will reduce the Revelle factor (i.e., increase the buffer capacity), through a better dissociation of $\mathrm{CO}_{2}$ into bicarbonate and carbonate. On the other hand, the Revelle factor increases with rising $p \mathrm{CO}_{2}$ (Zeebe and Wolf-Gladrow, 2001). In order to estimate the changes in Revelle factor due to climate change (i.e., increase in SST) as well as due to increase in surface $p \mathrm{CO}_{2}$, we compute the difference between the Revelle factor for year 2099 and year 1850 from the COU and UNC simulation, as shown in Fig. 13a and b. The Revelle factor is estimated using the formulation from Maier-Reimer and Hasselmann (1987). Generally, there is an agreement in increasing Revelle factor in the future, hence, lower buffer capacity of seawater to take up $\mathrm{CO}_{2}$. For most regions, Fig. 13b resembles well the spatial pattern of Fig. 13a (i.e., higher values in high latitude and relatively small changes in low latitude). The similarity between the Revelle factor changes simulated in the COU and UNC suggests that changes in surface $p \mathrm{CO}_{2}$ (instead of climate change) may dominate the future Revelle factor variation. In several high latitude regions, such as northwestern Pacific and the Southern Ocean (south of $60^{\circ} \mathrm{S}$ ), the simulated warming in SST of as much as $5^{\circ} \mathrm{C}$ maintain the Revelle factor similar or lower than that of the pre-industrial period. In addition, we can estimate the future changes of the Revelle factor attributed to only climate change by computing the difference in Revelle factor between the COU and UNC simulations for year 2099 (shown in Fig. 13c). Fi- gure $13 \mathrm{c}$ demonstrates that warming in parts of the Southern Ocean and northwestern Pacific induces lower Revelle factor. On the other hand, cooling in the North Atlantic sub-polar gyre slightly increases the Revelle factor in that region.

\section{Discussion and conclusions}

In this study, we coupled terrestrial (LPJ) and oceanic (HAMOCC5) global carbon cycle modules into the Bergen Climate Model (BCM). Our results show that the BCM-C model is able to simulate relatively well the temporal and spatial variabilities of the observed present climate and carbon cycle processes. The simulated future projection of atmospheric $\mathrm{CO}_{2}$ concentration as well as global oceanic and terrestrial carbon uptake lies well within range of other Earth system models. Nevertheless, we note that the current model does not allow the terrestrial vegetation to feedback to the atmosphere by changing the surface albedo. The model also ignores the terrestrial nitrogen cycle and the spatial variability of atmospheric $\mathrm{CO}_{2}$ concentrations.

The fully coupled climate-carbon cycle model (BCM-C) is integrated for the period $1850-2100$ and forced by prescribed historical and IPCC SRES-A2 $\mathrm{CO}_{2}$ emission scenarios. In order to assess the mechanisms controlling the climate-carbon cycle feedback, two model simulations were generated, one where the climate change effect is included and one where it is suppressed. According to previous studies using complex three-dimensional Earth system models (Cox et al., 2000; Friedlingstein et al., 2006; Mikolajewicz et al., 2007), it is well accepted that future climate change is likely to reduce carbon uptake, retaining a larger fraction of airborne $\mathrm{CO}_{2}$ in the atmosphere. Our model simulations also show a decrease in the strength of carbon uptake, predominantly by the terrestrial reservoir, despite a continuous oceanic carbon uptake towards the end of the 21 st century. Nevertheless, previous feedback evaluations are mostly based on global assessments of the ocean and terrestrial reservoirs' ability in storing carbon in relation to changes in global atmospheric $\mathrm{CO}_{2}$ concentration and climate. Therefore, the regional effect of carbon cycling on climate variability and their controlling mechanisms remain poorly understood. In this study, we further analyzed the processes controlling the climate-carbon cycle feedbacks strength in different regions.

Over land, climate change mostly impacts the tropical and northern high latitude regions. While an increase in ambient $\mathrm{CO}_{2}$ concentrations stimulates net primary production and increases carbon storage in plant tissues, the consequences of warming generally lead to an increase in terrestrial soil respiration, and thus, induce carbon outgassing. The tropical regions respond most strongly to changes in the atmospheric $\mathrm{CO}_{2}$ concentrations because plant assimilation of $\mathrm{CO}_{2}$ is more efficient under warmer conditions. Higher soil respiration rates due to warming lead to a decline in soil-carbon 
turnover time, predominantly at high latitudes where the change in surface temperatures is at a maximum.

In this study, the dynamical vegetation schemes improve the climate-carbon cycle feedback estimate since it allows the PFTs (i.e., Plant Functional Type) to respond to warmer climate. Nevertheless, a more realistic estimation of the terrestrial biosphere feedback requires the inclusion of land-use changes, whose impact is expected to be in the same order of magnitude as that of the vegetation regime shifts.

Unlike the terrestrial carbon cycle, there is relatively less change in the simulated global carbon uptake by the ocean between the COU and UNC. Regional analysis indicates that different processes in different parts of the world ocean contribute to dampen the relatively small carbon uptake changes between the two simulations. In addition, the consequences of climate change on ocean carbon uptake are not clearly apparent until the second half of this century.

Our study shows that there are both direct and indirect effects of climate change in altering oceanic carbon uptake. The direct effects include an increase in SST, which directly decreases the $\mathrm{CO}_{2}$ gas solubility in seawater, most pronounced in high-latitude regions. While increase in SST could also lead to a reduced Revelle factor (i.e., better $\mathrm{CO}_{2}$ buffer capacity), our analysis shows that the simulated changes in Revelle factor are mostly dominated by changes in surface $p \mathrm{CO}_{2}$, rather than SST. Additionally, changes in atmospheric circulation (i.e., surface wind stress) tend to enhance the transfer rate of carbon across the air-sea interface, also most pronounced in high-latitude regions, especially in regions where the sea ice retreats. On average, changes in solubility and gas transfer rate of $\mathrm{CO}_{2}$ alone would tend to decrease and increase carbon uptake by the ocean, respectively.

The indirect effects of climate change include, but are not limited to, changes in ocean circulation dynamics, mixed layer depth, sea-ice extent and fresh water fluxes. These indirect climate change factors significantly affect the high latitude Southern Ocean region. The summer sea ice extent in Antarctica, as simulated by the model, reduces almost to zero due to warming. This retreat of sea ice induces stronger $\mathrm{CO}_{2}$ gas transfer and deeper mixed layers, which in turn increase the transfer of carbon from the atmosphere to the ocean as well as from the surface into larger depths. A similar response to indirect effects of climate change is also shown in the Arctic region, where the model simulates a reduction of $\sim 25 \%$ in sea ice extent. Over most of the North Atlantic regions, warming leads to shallowing of mixed layer depths and a slowdown of the overturning circulation, which favours the reduction of the vertical transport of surface DIC into deeper layers.

Acknowledgements. The authors would like to thank Martin Miles, Andy Ridgwell, and the anonymous referees for thoroughly reviewing the manuscript. We are also very grateful to Pierre Friedlingstein and the C4MIP group for the support and access to the original C4MIP data (used in Figs. 3 and 5). This study at the University of Bergen and Bjerknes Centre for Climate Research is supported by the EU-FP6 integrated project CarboOcean (grant nr. 511176), the Research Council of Norway funded project NorClim and CarboSeason (grant nr. 185105/530). We acknowledge the Norwegian Metacenter for Computational Science and Storage Infrastructure (NOTUR and NorStore, "Biogeochemical Earth system modelling" project nn2980k and ns2980k) for providing the computing and storing resources essential for this study. This is publication no. A266 from the Bjerknes Centre for Climate Research.

Edited by: A. Ridgwell

\section{References}

Assmann, K. M., Bentsen, M., Segschneider, J., and Heinze, C.: An isopycnic ocean carbon cycle model, Geosci. Model Dev. Discuss., 2, 1023-1079, 2009.

Aumont, O., Maier-Reimer, E., Blain, S., and Monfray, P.: An ecosystem model of the global ocean including $\mathrm{Fe}$, Si, P colimitations, Global Biogeochem. Cy., 17, 1060, doi:10.1029/2001GB001745, 2003.

Bleck, R., Rooth, C., Hu, D., and Smith, L. T.: Salinity-driven thermocline transients in a wind- and thermohaline-forced Isopycnic Coordinate Model of the North Atlantic, J. Phys. Oceanogr., 22, 1486-1505, 1992.

Bossuet, C., Déqué, M., and Cariolle, D.: Impact of a simple parameterization of convective gravity-wave drag in a stratospheretroposphere general circulation model and its sensitivity to vertical resolution, Ann. Geophys., 16, 238-249, 1998, http://www.ann-geophys.net/16/238/1998/.

Catry, B., Geleyn, J.-F., Bouyssel, F., Cedilnik, J., Brozkova, R., Derkova, M., and Mladek, R.: A new sub-grid scale lift for- mulation in a mountain drag parameterisation scheme, Meteorol. Z., 17, 193-208, 2008.

Cox, P. M., Betts, R. A., Jones, C. D., Spall, S. A., and Totterdell, I. J.: Acceleration of global warming due to carbon cycle feedback in a coupled climate model, Nature, 408, 184-188, 2000.

Cramer, W., Bondeau, A., Woodward, F. I., Prentice, I. C., Betts, R. A., Brovkin, V., Cox, P. M., Fisher, V., Foley, J. A., Friend, A. D., Kucharik, C., Lomas, M. R., Ramankutty, N., Sitch, S., Smith, B., White, A., and Young-Molling, C.: Global response of terrestrial ecosystem structure and function to $\mathrm{CO}_{2}$ and climate change: results from six dynamic global vegetation models, Glob. Change Biol., 7, 357-373, 2001

Crueger, T., Roeckner, E., Raddatz, T., Schnur, R., and Wetzel, P.:Ocean dynamics determine the response of oceanic $\mathrm{CO}_{2}$ uptake to climate change, Clim. Dynam., 31, 151-168, doi:10.1007/s00382-007-0342-x, 2008.

de Szoeke, R. A.: Equation of motion using thermodynamic coordinates, J. Phys. Oceanogr., 29, 2719-2729, 2000.

Déqué, M., Dreveton, C., Braun, A., and Cariolle, D.: The ARPEGE/IFS atmosphere model: A contribution to the French community climate modelling, Clim. Dynam., 12, 37-52, 1994.

Douville, H., Royer, J. F., and Mahfouf, J. F.: A new snow parameterization for the Météo-France climate model. Part II: Validation in a 3D GCM experiment, Clim. Dynam., 12, 37-52, 1995. 
Drange, H. and Simonsen, K.: Formulation of air-sea fluxes in the ESOP2 version of MICOM, Technical Report 125, Nansen Environmental and Remote Sensing Center, Bergen, Norway, 23 pp., 1996.

Dukowicz, J. K. and Baumgardner, J. R.: Incremental remapping as a transport/advection algorithm, J. Comput. Phys., 160, 318-335, 2000.

Farquhar, G. D., von Caemmerer, S., and Berry, J. A.: A biochemical model of photosynthetic $\mathrm{CO}_{2}$ assimilation in leaves of $\mathrm{C}_{3}$ species, Planta, 149, 78-90, 1980.

Friedlingstein, P., Cox, P., Betts, R., Bopp, L., et al.: Climatecarbon cycle feedback analysis: Results from the $\mathrm{C}^{4} \mathrm{MIP}$ model intercomparison, J. Climate, 19, 3337-3353, 2006.

Friedlingstein, P., Cox, P., Betts, R., Bopp, L., von Bloh, W., Brovkin, V., Cadule, P., Doney, S., Eby, M., Fung, I., Gala, B., John, J., Jones, C., Joos, F., Kato, T., Kawamiya, M., Knorr, W., Lindsay, K., Matthews, H. D., Raddatz, T., Rayner, P., Reick, C., Roeckner, E., Schnitzler, K.-G., Schnur, R., Strassmann, K., Weaver, A. J., Yoshikawa, C., and Zeng, N.: Climate-carbon cycle feedback analysis: Results from the $\mathrm{C}^{4} \mathrm{MIP}$ model intercomparison, J. Climate, 19, 3337-3353, 2006.

Furevik, T., Bentsen, M., Drange, H., Kindem, I. K. T., Kvamstø, N. G., and Sorteberg, A.: Description and evaluation of the bergen climate model: ARPEGE coupled with MICOM, Clim. Dynam., 21, 27-51, doi:10.1007/s00382-003-0317-5, 2003.

Gaspar, P.: Modeling the seasonal cycle of the upper ocean, J. Phys. Oceanogr., 18, 161-180, 1988.

Geleyn, J.-F.: Interpolation of wind, temperature and humidity values from model levels to the height of measurement, Tellus A, 40, 347-351, 1988.

Harder, M.: Dynamik, Rauhigkeit und Alter des Meereises in der Arktis, Ph.D. thesis, Alfred-Wegener-Institut für Polar-und Meeresforschung, Bremehaven, Germany, 124 pp., 1996.

Heimann, M. and Reichstein, M.: Terrestrial ecosystem carbon dynamics and climate feedbacks, Nature, 451, 289-292, doi:10.1038/nature06591, 2008.

Hickler, T., Smith, B., Prentice, I. C., Mjöfors, K., Miller, P., Arneth, A., and Sykes, M. T.: $\mathrm{CO}_{2}$ fertilization in temperate FACE experiments not representative of boreal and tropical forests, Glob. Change Biol., 14, 1531-1542, doi: 10.1111/j.13652486.2008.01598.x, 2008.

Houghton, R. A. and Hackler, J. L.: Carbon flux to the atmosphere from land-use changes. Trends: A compendium of data on global change, Carbon Dioxide Information Analysis Center, US Department of Energy, Oak Ridge, TN, USA, 2002.

Janic, Z. I.: Pressure gradient force and advection scheme used for forecasting with steps and small scale topography, Beitr. Phys. Atmos., 50, 186-199, 1977.

Kraus, E. B. and Turner, J. S.: A one dimensional model of the seasonal thermocline - II. The general theory and its consequences, Tellus, 19, 98-105, 1967.

Kucharik, C. J., Foley, J. A., Delire, C., Fisher, V. A., Coe, M. T., Lenters, J. D., Young-Molling, C., Ramankutty, N., Norman, J. N., and Gower, S. T.: Testing the performance of a dynamic global ecosystem model: water balance, carbon balance, and vegetation structure, Global Biogeochem. Cy., 14, 795-825, 2000.

Lott, F. and Miller, M. J.: A new subgrid-scale orographic drag parameterization: Its formulation and testing, Q. J. Roy. Meteor.
Soc., 123, 101-127, 1997.

Lott, F.: Alleviation of stationary biases in a GCM through a mountain drag parameterization scheme and a simple representation of mountain lift forces, Mon. Weather Rev., 125, 788-801, 1999.

Louis, J.: A parametric model of vertical eddy fluxes in the atmosphere, Bound.-Lay. Meteorol., 17, 187-202, 1979.

Louis, J., Tiedtke, M., and Geleyn, J.-F.: A short history of the operational PBL parameterization at ECMWF, in: Proceedings of ECMWF workshop on planetary boundary layer parameterization, November 1981,, ECMWF, Reading, England, 59-80 1982.

Luo, Y.: Terrestrial carbon cycle feedback to climate warming, Annu. Rev. Ecol. Evol. S., 38, 683-712, doi:10.1146/annurev.ecosys.38.091206.095808, 2007.

Maier-Reimer, E.: Geochemical cycles in an ocean general circulation model. Preindustrial tracer distribution, Global Biogeochem. Cy., 7, 645-677, 1993.

Maier-Reimer, E. and Hasselmann, K.: Transport and storage of $\mathrm{CO}_{2}$ in the ocean-an inorganic ocean-circulation carbon cycle model, Clim. Dynam., 2, 63-90, 1987.

Maier-Reimer, E., Kriest, I., Segschneuder, J., and Wetzel, P.: The HAMburg Ocean carbon cycle Model HAMOCC5.1 - Technical Description Release 1.1, Berichte zur Erdsystemforschung 14, ISSN 1614-1199, Max Planck Institute for Meteorology, Hamburg, Germany, 50 pp., 2005.

Marland, G., Boden, T. A., and Andres, R. J.: Global, regional, and national $\mathrm{CO}_{2}$ emissions. Trends: A compendium of data on global change, Carbon Dioxide Information Analysis Center, US Department of Energy, Oak Ridge, TN, USA, 2005.

McDougall, T. J. and Dewar, W. K.: Vertical mixing and cabbeling in layered models, J. Phys. Oceanogr., 28, 1458-1480, 1998.

McDougall, T. J. and Jackett, D. R.: An assessment of orthobaric density in the global ocean, J. Phys. Oceanogr., 35, 2054-2075, 2005.

Mikolajewicz, U., Groger, M., Maier-Reimer, E., Schurgers, G., Vizcaíno, M., and Winguth, A. M. E.: Long-term effects of anthropogenic $\mathrm{CO}_{2}$ emissions simulated with a complex earth system model, Clim. Dynam., 28, 599-631, 2007.

Otterå, O. H, Bentsen, M., Bethke, I., and Kvamstø, N. G.: Simulated pre-industrial climate in Bergen Climate Model (version 2): model description and large-scale circulation features, Geosci. Model Dev., 2, 197-212, 2009.

Randall, D. A., Wood, R. A., Bony, S., Colman, R., Fichefet, T., Fyfe, J., Kattsov, V, Pitman, A., Shukla, J., Srinivasan, J., Stouffer, R. J., Sumi, A., and Taylor, K. E.: Climate models and their evaluation, in: Climate Change, edited by: Solomon, S., Qin, D., Manning, M., Chen, Z., Marquis, M., Averyt, K. B., Tignor, M., and Miller, H. L., Cambridge University Press, Cambridge, United Kingdom and New York, 589-662, 2007.

Sabine, C. L., Feely, R. A., Gruber, N., Key, R. M., Lee, K., Bullister, J. L., Wanninkhof, R., Wong, C. S., Wallace, D. W. R., Tilbrook, B., Millero, F. J., Peng, T.-H., Kozyr, A., Ono, T., and Rios, A. F.: The oceanic sink for anthropogenic $\mathrm{CO}_{2}$, Science, 305, 367-371, 2004.

Salas-Melia, D: A global coupled sea ice-ocean model, Ocean Model., 4, 137-172, 2002.

Schmittner, A., Latif, M., and Schneider, B.: Model projections of the North Atlantic thermohaline circulation for the 21st century assessed by observations, Geophys. Res. Lett., 32, L23710, doi:10.1029/2005GL024368, 2005. 
Sitch, S., Huntingford, C., Gedney, N., Levy, P. E., Lomass, M., Piao, S. L., Betts, R., Ciais, P., Cox, P., Friedlingstein, P., Jones, C. D., Prentice, I. C., and Woodwards, F. I.: Evaluation of the terrestrial carbon-cycle future plant geography and climate carbon cycle feedbacks using five Dynamic Global Vegetation Models (DGVMs), Glob. Change Biol., 14, 2015-2039, 2008.

Sitch, S., Smith, B., Prentice, I. C., Arneth, A., Bondeau, A., Cramer, W., Kaplan, J. O., Levis, S., Lucht, W., Sykes, M. T., Thonicke, K., and Venevsky, S.: Evaluation of ecosystem dynamics, plant geography and terrestrial carbon cycling in the LPJ dynamic global vegetation model, Glob. Change Biol., 9, 161185, 2003.

Six, K. and Maier-Reimer, E.: Effects of plankton dynamics on seasonal carbon fluxes in an ocean general circulation model, Global Biogeochem. Cy., 10, 559-583, 1996.

Takahashi, T., Sutherland, S. C., Wanninkhof, R., Sweeney, C., Feely, R. A., Chipman, D. W., Hales, B., Friedrich, G., Chavez, F., Sabine, C., Watson, A., Bakker, D. C. E., Schuster, U., Metzl, N., Yoshikawa-Inoue, H., Ishii, M., Midorikawa, T., Nojiri, Y., Kōrtzinger, A., Steinhoff, T., Hoppema, M., Olafsson, J., Arnarson, T. S., Tilbrook, B., Johannessen, T., Olsen, A., Bellerby, R., Wong, C. S., Delille, B., Bates, N. R., and de Baar, H. J. W.: Climatological mean and decadal change in surface ocean $p \mathrm{CO}_{2}$, and net sea-air $\mathrm{CO}_{2}$ flux over the global oceans, DeepSea Res. Pt. II, 56(8-10), 554-577, 2009.
Taylor, K. E.: Summarizing multiple aspects of model performance in a single diagram, J. Geophys. Res., 106, 7183-7192, 2001.

Terray, L., Thual, O., Belamari, S., Déqué, M., Dandin, P., Lévy, C., and Delecluse, P.: Climatology and interannual variability simulated by the arpege-opa model, Clim. Dynam., 11, 487-505, 1995.

Tjiputra, J. F. and Winguth, A. M. E.: Sensitivity of sea-to-air $\mathrm{CO}_{2}$ flux to ecosystem parameters from an adjoint model, Biogeosciences, 5, 615-630, 2008, http://www.biogeosciences.net/5/615/2008/.

Wanninkhof, R.: Relationship between wind speed and gas exchange over the ocean, J. Geophys. Res., 97, 7373-7382, 1992.

Weiss, R. F.: The solubility of nitrogen, oxygen and argon in water and sea water, Deep-Sea Res., 17, 721-735, 1970.

Weiss, R. F.: Carbon dioxide in water and seawater: The solubility of a non-ideal gas, Mar. Chem., 2, 203-215, 1974.

Zeebe, R. E. and Wolf-Gladrow, D. E.: $\mathrm{CO}_{2}$ in seawater: Equilibrium. Kinetics, Isotops, Elsevier Oceanography Series, Amsterdam, 65, 346 pp., 2001.

Zickfeld, K., Eby, M., and Weaver, A. J.: Carbon-cycle feedbacks of changes in the Atlantic meridional overturning circulation under future atmospheric $\mathrm{CO}_{2}$, Global Biogeochem. Cy., 22, GB3024, doi:10.1029/2007GB003118, 2008. 